\title{
Immunoproteasome deficiency alters microglial cytokine response and improves cognitive deficits in Alzheimer's disease-like APPPS1 mice
}

Lisa K. Wagner ${ }^{1,2}$, Kate E. Gilling ${ }^{3}$, Eileen Schormann ${ }^{3}$, Peter M. Kloetzel ${ }^{3}$, Frank L. Heppner ${ }^{1,4,5^{*}}$, Elke Krüger ${ }^{3,5,6^{*}+}$ and Stefan Prokop ${ }^{1,7 \dagger}$ (D)

\begin{abstract}
The immunoproteasome (iP) represents a specialized type of proteasomes, which plays an important role in the clearance of oxidant-damaged proteins under inflammatory and pathological conditions determining the outcome of various diseases. In Alzheimer's disease (AD)-like APPPS1 mice Aß-deposition is paralleled by iP upregulation, most likely mediated through type I interferon induction. To define the impact of increased iP expression we crossed APPPS1 mice with mice deficient in the iP subunit LMP7 resulting in impaired iP function. While LMP7 deficient APPPS1 mice showed no major change in cerebral A $\beta$-pathology, we observed an altered cytokine response in microglia isolated from LMP7 deficient APPPS1 mice compared to LMP7 expressing APPPS1 control mice. The altered microglial cytokine profile upon iP deficiency in the presence of extracellular A $\beta$-pathology was associated with an improvement of A $\beta$-associated cognitive deficits typically present in APPPS1 mice. Our findings suggest a role for iP in the regulation of the innate immune response towards extracellular $A \beta$-pathology and indicate that inhibition of iP function can modulate the cognitive phenotype upon overexpression of $A \beta$.
\end{abstract}

Keywords: Proteasome, Immunoproteasome, Microglia, Inflammation, Alzheimer's disease

\section{Significance statement}

We herein show that the immunoproteasome (iP) significantly modulates microglial pro-inflammatory cytokine secretion in a murine model of $\mathrm{AD}$ and alters the pathology-associated behavioral phenotype in these mice. Since iP impairment did not affect $A \beta$ plaque burden our data demonstrate that inflammation has a critical effect on cognitive outcome independent of A $\beta$-pathology. Our study links iP function, the innate immune response and cognitive performance for the first time in an in vivo model of neurodegeneration and suggests that modulation of the iP is a viable option for the treatment of AD.

\footnotetext{
* Correspondence: frank.heppner@charite.de; elke.krueger@uni-greifswald.de ${ }^{\dagger}$ Equal contributors

${ }^{1}$ Department of Neuropathology, Charité - Universitätsmedizin Berlin, Charitéplatz 1, 10117 Berlin, Germany

${ }^{3}$ Institute of Biochemistry, Charité - Universitätsmedizin Berlin, Charitéplatz 1, 10117 Berlin, Germany

Full list of author information is available at the end of the article
}

\section{Introduction}

The ubiquitin-proteasome system (UPS) is a major regulator of protein homeostasis, vital to regulatory processes via degradation of short-lived proteins involved in the cell cycle, differentiation, transcriptional regulation or apoptosis, and is also important for the degradation of misfolded and damaged proteins [22, 28]. Proteins destined for degradation are labelled with a poly-ubiquitin tag, which is recognized by the $19 \mathrm{~S}$ regulatory cap of the $26 \mathrm{~S}$ proteasome and broken down by the $20 \mathrm{~S}$ core containing the three catalytically active $\beta 1, \beta 2$ and $\beta 5$ subunits. The immunoproteasome (iP) is an isoform, which is constitutively expressed in immune cells and induced by pro-inflammatory cytokines such as type I and type II interferons (IFNs) in almost any other cell type. IFN signaling leads to incorporation of the alternative catalytically activite $\beta$ subunits $\beta 1 \mathrm{i} / \mathrm{LMP} 2, \beta 2 \mathrm{i} / \mathrm{MECL}-1$ and $\beta 5 \mathrm{i} / \mathrm{LMP7}$ into newly formed iPs $[1,28]$. There are subtypes of iPs which contain only one or two $\beta \mathrm{i}$ subunits 
[54], however the $\beta 5 \mathrm{i} / \mathrm{LMP7}$ subunit is indispensable for iP formation [40]. Depending on the tissue and specific cells types, different proteasome compositions are expressed and can coexist [7]. Previous studies have demonstrated that iPs possess enhanced overall activity compared to standard proteasomes [49] and extended the role of iPs; under conditions of cellular stress and inflammation, the inducible forms of proteasomes were shown to be vital for the degradation of misfolded and oxidant-damaged proteins to prevent disease progression $[40,49]$. Moreover, patients harboring mutations in proteasome subunit genes that cause proteasome associated autoinflammatory syndromes (PRAAS) with proteasome dysfunction combined with concomitant proteotoxic stress, exhibit increased type I IFN production $[7,8]$.

Notably, the UPS also appears to be implicated in the pathogenesis of neurodegenerative diseases [3, 12, 15] such as Alzheimer's disease (AD), the most common neurodegenerative disorder [44]. Previous work has shown that ubiquitinylated protein deposits accumulate in the brains and cerebrospinal fluid of $\mathrm{AD}$ patients $[19,24,34,38,42,56,58]$ and in rodent models of disease [33]. A malfunction of the UPS was reported in AD patients [27] and mouse models involving extracellular beta-amyloid $(\mathrm{A} \beta)$ deposits $[41,48]$. However, it is still unclear whether the presence of $A \beta$ leads to proteasomal impairment or if disrupted proteasome activity enhances cellular toxicity. Besides intense investigations on the function of the standard proteasome, recent publications demonstrate an upregulation of the iP in microglia and astrocytes surrounding $A \beta$ plaques in a mouse model of $\mathrm{AD}$, as well as positive correlation of iP activity with increasing severity of tau pathology in AD patients $[2,41]$. However, the precise role of iPs in regulating the innate immune response towards $A \beta$ deposits and a potential impact of a modulation of iP activation on disease course and cognitive function has not been explored in vivo so far.

To pinpoint the involvement of the iP in $\mathrm{A} \beta$-pathology, we analyzed the expression of iP subunits during the course of normal aging and in AD-like pathology in APPPS1 mice [45]. To further dissect the role of iPs in AD-like pathology, we crossed APPPS1 mice to $\beta 5 \mathrm{i} / \mathrm{LMP} 7$ deficient mice lacking exons $1-5$ of the proteasome subunit beta type 8 (PSMB8) gene, which encodes for the catalytic iP subunit $\beta 5 \mathrm{i} / \mathrm{LMP} 7$ and is inevitable for iP formation, resulting in a loss of iP assembly in LMP7 deficient mice [18].

Here we show that iP expression is increased upon aging and accelerated by the onset of $A \beta$-pathology. While the lack of LMP7 had no impact on the development and progression of $A \beta$ burden in APPPS1 mice, the pattern of cytokines secreted by microglia was significantly altered, resulting in an ameloriation of cognitive deficits typically found in APPPS1 mice. These data suggest that iPs contribute to the regulation of $A \beta$-driven innate immune responses and modulate cognitive deficits associated with $\mathrm{AD}$ pathology.

\section{Materials and methods \\ Animals and tissue collection}

APPPS1 mice harboring the Swedish amyloid precursor protein (APP) mutation KM670/671NL in conjunction with the presenilin 1 mutation L166P [45] were crossed to $\beta 5 \mathrm{i} / \mathrm{LMP} 7$ deficient mice [18], lacking exons 1 to 5 of proteasome (prosome, macropain) subunit beta type 8 (PSMB8) gene, that encodes for LMP7. All experiments used littermate mice of both genders. Mice were group housed under pathogen-free conditions on a $12 \mathrm{~h}$ light/ dark cycle, and food and water were provided to the mice ad libitum. All animal experiments were performed in accordance to the national animal protection guidelines approved by the regional offices for health and social services in Berlin (LaGeSo). Animals were euthanized and transcardially perfused with $1 \times$ phosphate buffered saline (PBS). Brains were carefully removed and fixed in $4 \%$ paraformaldehyde (PFA) for 2 days followed by immersion in 30\% sucrose for at least 1 day for immunohistochemical analysis or was snap-frozen in a 2-methylbutane (Merck) bath placed in liquid nitrogen for subsequent processing.

\section{Real time RT- PCR}

For isolation of RNA, brain tissue was homogenized in TRIzol $^{\circ}$ (Life Technologies) and centrifuged for $10 \mathrm{~min}$ at $12,000 \times \mathrm{g}\left(4{ }^{\circ} \mathrm{C}\right)$. The supernatant was mixed with chloroform, vigorously mixed and incubated for $3 \mathrm{~min}$ at room temperature. Samples were centrifuged for $15 \mathrm{~min}$ at $12,000 \times \mathrm{g}\left(4{ }^{\circ} \mathrm{C}\right)$ and the supernatant carefully removed, mixed with chilled isopropanol and incubated for $10 \mathrm{~min}$ at room temperature before a further $30 \mathrm{~min}$ centrifugation step at $12,000 \mathrm{x} \mathrm{g}\left(4{ }^{\circ} \mathrm{C}\right)$. The resulting pellet was dissolved in ethanol, centrifuged for $10 \mathrm{~min}$ at $7500 \times \mathrm{g}\left(4^{\circ} \mathrm{C}\right)$, and ethanol removed. This step repeated and the dry pellet dissolved in ultrapure $\mathrm{H}_{2} \mathrm{O}$. cDNA synthesis was performed using the Transcriptor High Fidelity cDNA Synthesis kit (Roche) according to the manufacturer's instructions.

Real time PCR using TaqMan gene expression assays (Applied Biosystems) for Hprt, PSMB9 (encoding LMP2); PSMB8 (encoding LMP7), Ifn- $\alpha$, Ifn- $\beta$, Isg15 and Cxcl10 (IP-10) were performed using a Rotor-Gene RG-3000 (Corbett Research).

\section{Proteasome activity assay}

Brain tissue was homogenized in TSDG buffer $(10 \mathrm{mM}$ Tris $\mathrm{pH}$ 7.0, $10 \mathrm{mM} \mathrm{NaCl}, 25 \mathrm{mM} \mathrm{KCl}, 1.1 \mathrm{mM} \mathrm{MgCl}$, $0.1 \mathrm{mM}$ EDTA, $1 \mathrm{mM}$ DTT, $2 \mathrm{mM}$ ATP, $10 \%$ glycerin) and underwent 5 cycles of freezing and defrosting using liquid nitrogen. Samples were centrifuged for $60 \mathrm{~min}$ at 
$13,000 \times \mathrm{g}\left(4^{\circ} \mathrm{C}\right)$ und protein concentration determined using the Pierce BCA Protein Assay Kit (Thermo Fischer) according to the manufacturers protocol. Samples were loaded onto a 96-well plate followed by the addition of the substrate Suc-Leu-Leu-Val-Tyr-AMC (Bachem). Plates were incubated at $37{ }^{\circ} \mathrm{C}$ for $90 \mathrm{~min}$ and fluorescence recorded using a Synergy-HT (Bio Tek) plate reader. To exclude non-proteasomal substrate degradation, samples were incubated for $10 \mathrm{~min}$ with epoxomicin $\left(1 \mu \mathrm{M} ; 37^{\circ} \mathrm{C}\right)$ before loading on the plate and values were substracted from lysates incubated with DMSO control. A standard sample of purified $26 \mathrm{~S}$ standard proteasome was loaded onto each plate, and measurements from samples were thereafter corrected against this control.

\section{Immunohistochemical staining}

Frozen tissue was cut in $30 \mu \mathrm{m}$ thick sections and stored free floating in cryoprotectant solution (30\% ethylenglycol, $20 \%$ glycerol, $50 \mathrm{mM}$ sodium phosphate buffer, $\mathrm{pH} 7.4$ ) at $4{ }^{\circ} \mathrm{C}$ until further use. For immunohistological staining, sections were rinsed in $1 \times \mathrm{PBS}$, incubated in blocking buffer ( $1 \times$ PBS containing $0,3 \%$ Triton X-100 and $10 \%$ normal goat serum) for $1 \mathrm{~h}$ at $\mathrm{RT}$ and primary antibodies for 4G8 (1:1000; Covance) and Iba-1 (1:500; Wako Chemicals) were diluted in $1 \times \mathrm{PBS} / 0.3 \%$ triton $\mathrm{X}-100 / 5 \%$ normal goat serum and incubated over night at $4{ }^{\circ} \mathrm{C}$. Sections were washed with $1 \times$ PBS to wash off excessive primary antibodies, incubated with species specific peroxidase-coupled secondary antibodies (goat anti-mouse or goat anti-rabbit (1:300, Dianova)) diluted in $1 \times \mathrm{PBS} / 0.3 \%$ Triton X-100/ 5\% normal goat serum and incubated for $1 \mathrm{~h}$ on a shaker at RT before developed with liquid diaminobezadine (DAB) (Dako, K3647). Sections were counterstained with matured hematoxylin followed by dehydration in an ascending alcohol series before covered using Roti ${ }^{\circ}$ Histokitt II mounting medium.

For Congo red staining, cerebral free floating sections were mounted on glass slides. Sections were incubated in stock solution I $(0.5 \mathrm{M} \mathrm{NaCl}$ in $80 \%$ ethanol, $1 \%$ $\mathrm{NaOH}$ ) for $20 \mathrm{~min}$ and in stock solution II $(8.6 \mathrm{mM}$ Congo red in stock solution I, $1 \% \mathrm{NaOH}$ ) for $45 \mathrm{~min}$. After rinsing twice in absolute ethanol, sections were counterstained with mature hematoxylin and dehydrated in ascending alcohol series, twice rinsed in $98 \%$ xylene for $1 \mathrm{~min}$, before mounting using Roti ${ }^{-}$-Histokitt II mounting medium. Light microscopy and stereology were performed using a Stereo Investigator system (MicroBrightField) and DV-47d camera (MicroBrightField) mounted on an Olympus BX53 microscope (Olympus, Germany). Fluorescence imaging was performed using an Olympus XM10 monochrome fluorescence CCD camera (Olympus, Germany).

\section{Stereological quantification}

Quantitative analyses of $\mathrm{A} \beta$ plaque load and numbers in cerebral cortical sections were performed using the Stereo Investigator system including an Olympus microscope BX53, the QImaging camera COLOR 12 BIT and a stage controller MAC 6000. For analyses, the Stereo Investigator 64-bit software (MBF Bioscience) was used. Cortical A $\beta$ plaque burden as assessed by 4 G8 or Congo red staining was quantified with the Area Fraction Fractionator method of the Stereo Investigator software as previously described [55]. Briefly, the area covered by $\mathrm{A} \beta$ was quantified using the following settings: counting frame size $90 \times 90 \mu \mathrm{m}$, scan grid size $400 \times 500 \mu \mathrm{m}$ and Cavallieri grid spacing $10 \mu \mathrm{m}$. Iba- $1+$ microglia area covered was assessed with cellSens software (Olympus) and the cortical region of interest was automatically analyzed according to manufacturer's instructions.

\section{Protein extraction}

Frozen brain tissue was homogenized according to a 4-step extraction method as described in [25] with slight modifications. In brief, hemispheres were homogenized consecutively in Tris buffered saline (TBS buffer) (20 mM Tris, $137 \mathrm{mM} \mathrm{NaCl}, \mathrm{pH}=7.6$ ), followed by a $45 \mathrm{~min}$ centrifugation step at $100,000 \times \mathrm{g}\left(4{ }^{\circ} \mathrm{C}\right)$. The supernatant was collected as the Tris soluble fraction and the pellet was resuspended in Triton-X buffer (TBS buffer containing 1\% Triton X-100). This was followed by further identical centrifugation and resuspension procedure and this cycle was repeated with SDS buffer (2\% SDS in $\mathrm{ddH}_{2} \mathrm{O}$ ) and formic acid (FA; $70 \%$ formic acid in $\mathrm{ddH}_{2} \mathrm{O}$ ). Immediately before use, protease inhibitors (Roche, 1 tablet per $10 \mathrm{ml}$ ) and a phosphatase inhibitor cocktail 3 (Sigma) were added to the first two buffers. Brain extracts were incubated $30 \mathrm{~min}$ on ice (except SDS and FA homogenates, which was incubated at RT) after resupending before centrifugation. Protein concentrations of each fraction were determined using the Quantipro BCA Protein Assay Kit (Pierce) according to the manufacturers protocol using the Tecan Infinite 200 M photometer (Tecan).

\section{Immunoblot and native PAGE analysis}

Expression levels of endogenous mouse and transgenic human APP and major C-terminal cleavage products of APP (CTF $\alpha$ and CTF) and LMP7 iP subunits were assessed by Western blot analysis according standard protocols [55]. SDS fractions of brain homogenates described above were analyzed using primary antibodies against $\beta 5 \mathrm{i} / \mathrm{LMP} 7$ (pc, K63, labstock generated against peptides of LMP7 protein; 1:5000; Prof. Peter M. Kloetzel, Institute of Biochemistry, Charité - Universitätsmedizin Berlin, Charitéplatz 1, 10,117 Berlin, Germany), APPct (Sigma, A8717); 1:1000) and GAPDH (Santa Cruz; 
1:2000). An HRP-conjugated anti-rabbit IgG antibody (GE healthcare) was used as secondary antibody and immunoreactive bands were visualized using the Amersham ECL immunoblotting detection system (GE healthcare). For native PAGE analysis, tissue was homogenized in TSDG buffer (10 mM Tris pH 7.0, $10 \mathrm{mM} \mathrm{NaCl}, 25 \mathrm{mM} \mathrm{KCl}$, $1.1 \mathrm{mM} \mathrm{MgCl} 2,0.1 \mathrm{mM}$ EDTA, $1 \mathrm{mM}$ DTT, $2 \mathrm{mM}$ ATP, $10 \%$ glycerin) and extracts loaded onto precast native PAGE gels (3\%-12\%, Invitrogen).

\section{Detection of $A \beta_{1-40}$ and $A \beta_{1-42}$ species and cytokines by multiplex mesoscale assays MSD}

$A \beta_{1-40}$ and $A \beta_{1-42}$ and cytokine concentrations in brain extracts and cell culture supernatants were determined with the MSD 96-Well MULTI-SPOT ${ }^{\oplus}$ Human (6E10) Abeta Triplex Assay (Meso Scale Discovery) or the V-PLEX ${ }^{\mathrm{su}}$ Mouse Cytokine Assay according to manufacturer's instructions and analyzed on a SECTOR Imager 6000 plate reader (Meso Scale Discovery).

\section{Microglia cell isolation and stimulation}

For cell isolation procedure, the whole brain was placed in HBSS on ice and further processed with neuronal kit dissociation according to manufactures instructions.

Isolation of $\mathrm{CD}_{11} \mathrm{~b}^{+}$cells from brain tissue was performed using the Neural Tissue Dissociation Kit (P) (Miltenyi Biotech) and the magnetic cell sorting (MACS) technique using CD11b-labeled magnetic Microbeads (Miltenyi Biotech) according to manufacturer's instructions.

$50.000 \mathrm{CD}_{11 \mathrm{~b}^{+}}$microglia were cultured overnight in a 96 well plate. Culture medium was removed and LPS $(1 \mu \mathrm{g} / \mathrm{ml})$ diluted in serum-free culture medium was added to stimulate the cells. Equivalent amount of PBS in serum-free medium was used as stimulation negative control. Supernatant for baseline measurements were collected prior to LPS stimulation. After $14 \mathrm{~h}$, medium was collected, snap frozen in liquid nitrogen and stored at $-80{ }^{\circ} \mathrm{C}$ for further cytokine analysis as described above.

\section{Behavioral analysis}

Cognition was assessed using the novel object recognition task (NOR) and the Barnes maze test at the age of 250 days. Experimenters were blinded during testing and data acquisition. All tests were performed in the animals' active phase in sound proof testing chambers with controlled temperature and humidity at the Berlin Animal Outcome Unit (NeuroCure Cluster of Excellence, Berlin, Germany). Experiments were conducted in a soundattenuated testing chamber with the illumination set at 30-40 lx. Mice were allowed to acclimate to the testing area for at least $30 \mathrm{~min}$ prior to testing. Each animal was allowed to explore freely for $5 \mathrm{~min}$ and activity was recorded with an overhead camera using an automated system (Viewer III Version 3.0.1.205, Biobserve, St.
Augustin, Germany). Animals were returned to their home cage at the end of the trial. Twenty-four hours after habituation, the animals were exposed to the familiar arena with two identical objects placed at an equal distance and allowed to explore for $5 \mathrm{~min}$. On the 3rd day, one of the familiar objects was exchanged for a different, novel object and the mice were allowed to explore the Open field in the presence of the familiar and novel objects for $5 \mathrm{~min}$. The time spent exploring each object and the number of visits to each object was recorded using an automated system (Viewer III Version 3.0.1.205, Biobserve, St. Augustin, Germany).

An elevated Barnes maze apparatus (TSE Systems $\mathrm{GmbH}$, Bad Homburg, Germany; diameter $920 \mathrm{~mm}$ ) containing 19 empty holes and one hole with a hidden escape chamber was used for testing spatial learning and memory. Animals were trained for the Barnes maze task for 4 days prior to testing. Each animal received 4 trials per day, spaced at 15 min intervals for each of the 4 days in order to learn the task. Extra-maze visual cues were placed around the room and remained consistent throughout the training and testing phase. During training, animals were allowed to freely explore for $3 \mathrm{~min}$ per trial. Bright lights (75-85 lx) and a loud white noise were used to motivate the animals to locate the escape box. The number of errors (nose-pokes into incorrect holes) and the latency to reach the target (hole with escape box) was scored. To test short-term spatial memory retention, one 90-s trial was conducted on day 5 wherein the escape box was removed. The time to reach the target hole (latency to target) and time spent in the target zone was measured. To test long-term memory retention, another 90-s trial was conducted 7 days later. Behavior was recorded using an overhead camera and automated software system (Viewer III Version 3.0.1.205, Biobserve, St. Augustin, Germany).

\section{Statistics}

Statistical analyses were performed using the GraphPad Prism 6 Software. Differences between two groups were evaluated by Student's t-test or Mann-Whitney test for pairwise comparison of experimental groups or by oneway ANOVA or two-way ANOVA with Bonferroni posttests for comparison of more than two experimental groups, as indicated. Data are represented as means $+/-$ SEM. Statistical significance is indicated as follows: * $p<0.05, * * * 0.01$ and ${ }^{* * * *} p<0.001$.

\section{Results}

Expression of iP subunits is increased during aging and is accelerated by A $\beta$-pathology in APPPS1 mice

Since previous data suggested an increase in iP gene expression during aging and in plaque-associated glia cells in APP/PS1 mice [41], we analyzed protein expression of 
LMP7 upon aging and in association with development of A $\beta$-pathology in brains of APPPS1 mice that show a more rapid $\mathrm{A} \beta$-pathology than the $\mathrm{APP} / \mathrm{PS} 1$ mice used in previous studies. While protein levels of LMP7 in brain homogenates were elevated during aging (from 49 to 250 days old mice, respectively) in wildtype littermate mice $\left(\mathrm{LMP7}^{+/+}\right.$: $49 \mathrm{~d}$ vs. $250 \mathrm{~d} ; p=0.0253$; two-way ANOVA followed by Bonferroni post-tests), this induction was significantly enhanced by the presence of $A \beta$-pathology in APPPS1 mice $\left(\mathrm{LMP}^{+/+}\right.$vs. APPPS1; $\mathrm{LMP7}^{+/+}$: 49d ns; 120d $p=0.0222$; 250d $p=0.0065$; two-way ANOVA followed by Bonferroni post-tests) (Fig. 1a-c). These changes in protein expression were reflected in alterations in total chymotryptic-like activity of the proteasome (standard proteasomes and iPs) (Fig. 1d) that was found to be significantly affected by $A \beta$-pathology in 250 days old APPPS1 mice $\left(\mathrm{LMP7}^{+/+}\right.$vs. $\mathrm{LMP7}^{-/-}: p=0,0061$ and $\mathrm{APPPS}_{1 ; \mathrm{LMP}^{+/+}}$vs. APPPS1;LMP7 ${ }^{-/-}: p=0.0001$; twoway ANOVA followed by Bonferroni post-tests) in which plaque pathology was fully established. For the latter age group, LMP7 deficiency resulted in significantly reduced chymotryptic-like activity, which can be accounted by the lack of functional iPs in the LMP7 deficient mice. $\mathrm{A} \beta$-related changes in iP subunit protein levels and function were paralleled by increased gene expression of the PSMB8 (encoding for LMP7) (120d: $\mathrm{LMP}^{+/+}$vs. APPPS1;LMP7 ${ }^{+/+}: p=0.0020$, and 250d: $\mathrm{LMP}^{+/+}$vs. APPPS1;LMP7 ${ }^{+/+}: p=0.0162$; two-way ANOVA followed by Bonferroni post-tests) and also another iP subunit gene PSMB9 (encoding for LMP2) at 120 and 250 days of age, respectively (Fig. 1e) (120d: $\mathrm{LMP}^{+/+}$vs. APPPS1;LMP7 ${ }^{+/+}$: $p=0.004$ and 250d: $\mathrm{LMP}^{+/+}$vs. APPPS1;LMP7 ${ }^{+/+}$: $p=0.0014$; two-way ANOVA followed by Bonferroni posttests). In contrast, there was no change in the expression of PSMB10 (encoding for $\beta 2 \mathrm{i} / \mathrm{Mecl}-1$ ).

To get a an insight in the regulation of iP subunit genes, we examined the transcription of other interferonstimulated genes, namely of the IFN-stimulated gene 15 (isg15) and of the IFN-inducible protein 10 gene ( $x$ cl10), both acting as chemokines in the brain and serve as indicators for type I IFN signaling. We found that their expression was not significantly affected by aging (Fig. 1f), while $A \beta$-pathology enhanced transcription of these genes significantly at 120 days of age (isg15: $\mathrm{LMP}^{+/+}$vs. APPPS1;LMP7 $7^{+/+}: p=0.0165$, and cxcl10: $\mathrm{LMP}^{+/+}$vs. APPPS1;LMP7 ${ }^{+/+}: p=0.0007$; two-way ANOVA followed by Bonferroni post-tests) indicating that increased iP expression and function are associated with exacerbated IFN-signaling in the brains of APPPS1 mice (Fig. 1f). Indeed, analysis of gene expression levels of type I interferons, namely ifn- $\alpha$ and ifn- $\beta$ revealed a transient upregulation of their transcription at 120 days of age (ifn- $\beta$ : $\mathrm{LMP7}^{+/+}$vs. APPPS1;LMP7 ${ }^{+/+}: p=0.0410$; two-way ANOVA followed by Bonferroni post-tests) (Fig. 1g).
Thus, increased iP expression in APPPS1 mice is most likely driven by type I IFN signaling.

IFN-signaling as well as AD have been shown to induce oxidative damage to proteins. Since oxidatively damaged proteins tagged by poly-ubiquitin conjugates are a target for iPs [49], we analyzed the levels of poly-ubiquitinylated proteins by Western blot. As expected, we observed a significant increase of poly-ubiquitinylated proteins upon development of $\mathrm{A} \beta$-pathology in APPPS1;LMP7 $7^{+/+}$mice compared to wild-type littermate control animals. However, the deficiency in iP subunits did not affect the levels of poly-ubiquitinylated proteins in APPPS1;LMP7 ${ }^{-1-}$ mice (Fig. 1h and i) suggesting an upregulation of standard proteasome (sP) activity during the development of A $\beta$-pathology. Since iPs are reported to be essential for cell viability, the amount of oxidant damaged proteins were analyzed indirectly by Western blot using an antiDNP antibody directed against ROS- changed carbonyl groups of proteins. Indeed, iPs are essential for cell viability as the amount of irreversibly damaged proteins is significantly increased upon iP subunit deficiency in $\mathrm{LMP}^{-/-}$mice compared to $\mathrm{LMP7}^{+/+}$littermate control mice (Fig. $1 \mathrm{j}$ and $\mathrm{k}$ ). However, the concentration of damaged proteins is not further changed during A $\beta$-pathology.

\section{LMP7 deficiency does not affect A $\beta$-pathology in APPPS1 mice}

To test the potential impact of the observed increase in iP expression levels on $A \beta$-plaque pathology in vivo, we assessed the development and progression of $A \beta$ pathology in presence or absence of iP activity in APPPS1 mice harboring or lacking LMP7. Stereological quantification revealed no difference in $A \beta$ plaque burden in brains of APPPS1 mice with or without functional LMP7 during the onset of A $\beta$-pathology (120 days of age; Fig. 2a and b; left panel), as well as in aged APPPS1 mice exhibiting extensive A $\beta$-pathology (250 days of age, Fig. $2 a$ and b, right panel). In addition, the distribution of plaque sizes was similar in both experimental groups (Fig. 2c and d). Biochemical analyses of total A $\beta$-levels (Fig. 2e) as well as detailed analyses of soluble and insoluble $A \beta$-species (Fig. $2 \mathrm{f}$ and g) corroborated these findings. Moreover, expression of the amyloid precursor protein (APP) and APP processing were unaltered in APPPS1 mice lacking or harboring LMP7 (Fig. 3a-h). Furthermore, the amyloidogenic APP $\beta-C$ terminal fragment released from APP by BACE cleavage remained unchanged (Fig. 3i). These data demonstrate that iP deficiency does not alter the development of A $\beta$-pathology in APPPS1 mice, does not affect size and solubility of $\mathrm{A} \beta$-deposits and does not affect APP processing. 

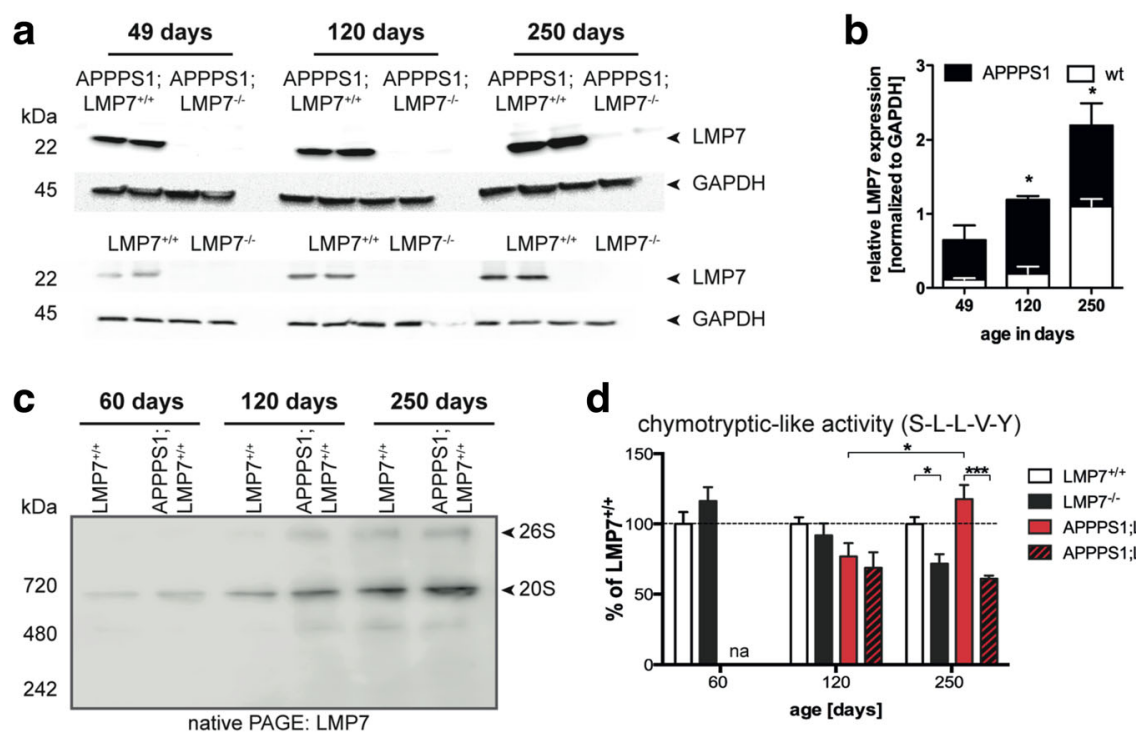

d chymotryptic-like activity (S-L-L-V-Y)
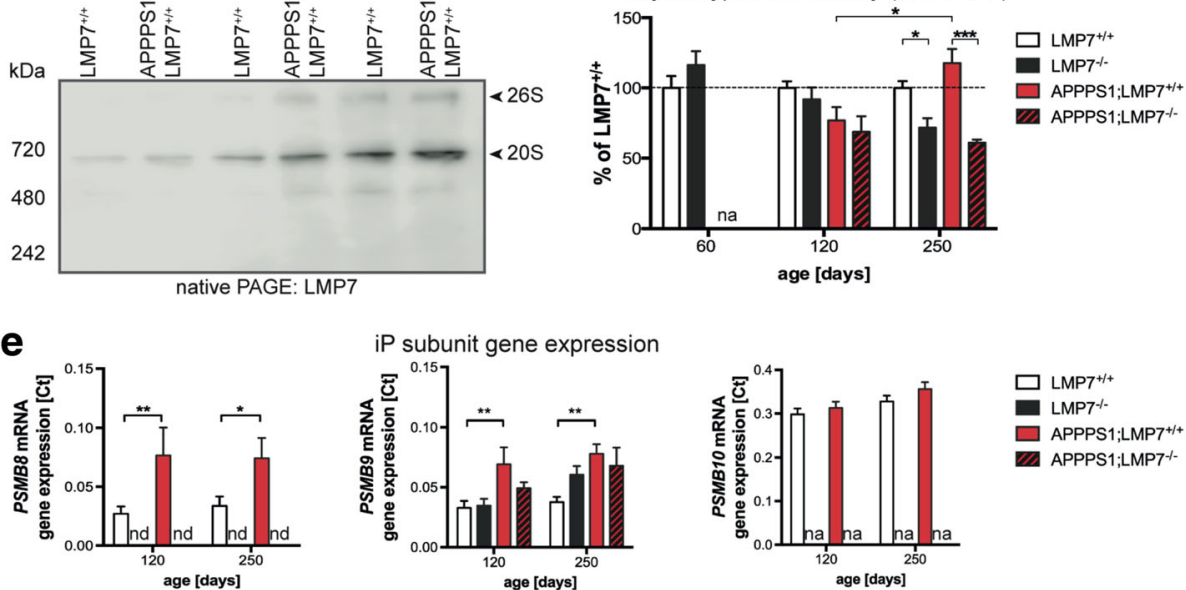

f

IFN stimulated genes
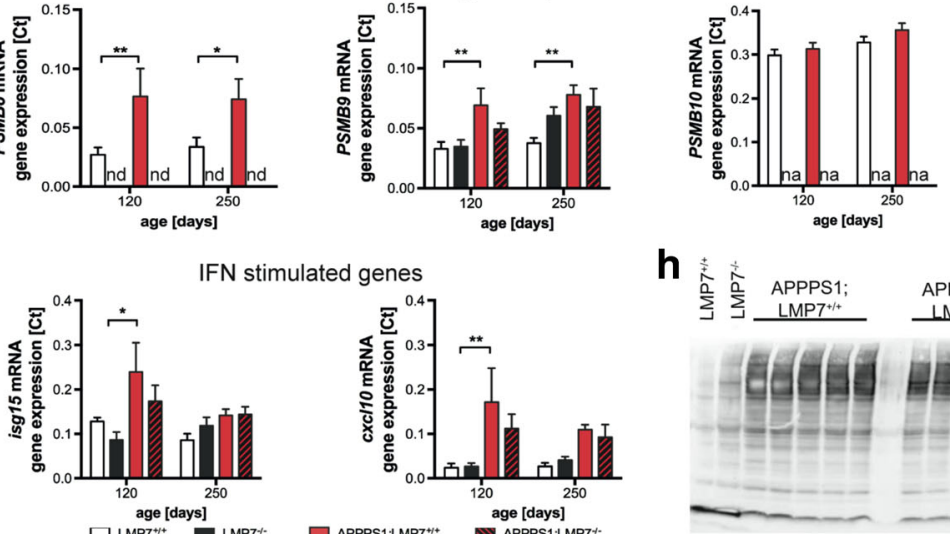

$\square \mathrm{LMPP}^{+1+}$

APPPS1:LMP7 $7^{++}$

APPPS1:LMP7-

g

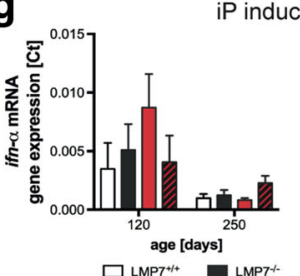

cytokines

h

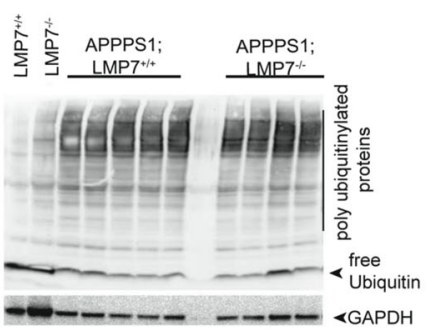

j

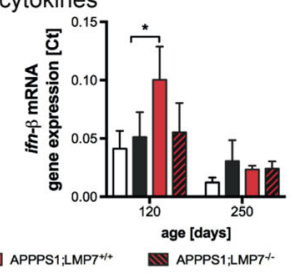

i
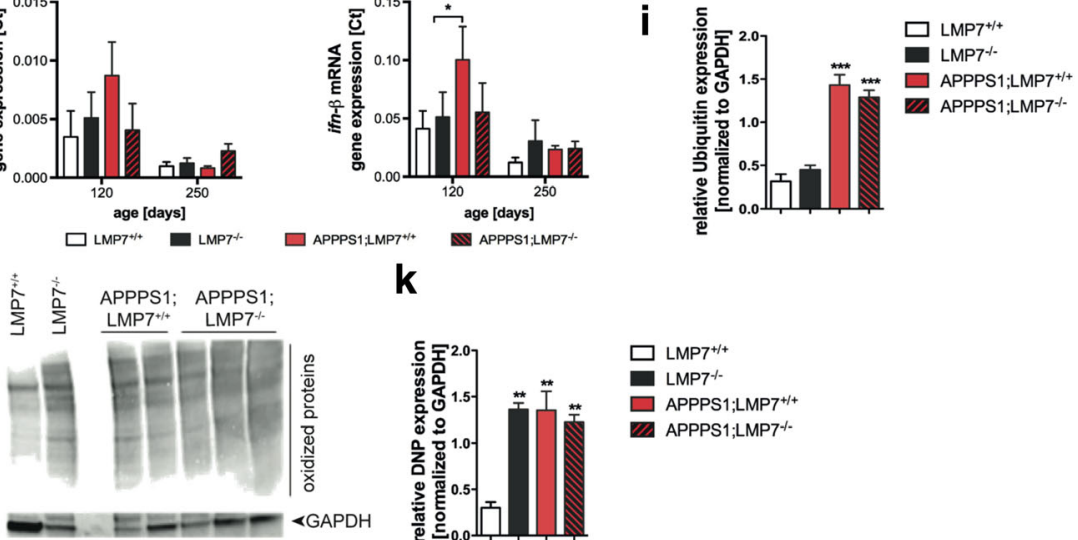

k

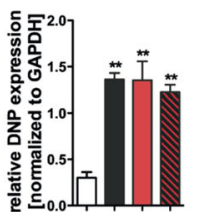

Fig. 1 (See legend on next page.) 


\begin{abstract}
(See figure on previous page.)
Fig. 1 iP subunit expression in the brain is increased upon aging and enhanced in APPPS1 mice. a Western blot analysis of LMP7 expression in brain homogenates of $49 \mathrm{~d}, 120 \mathrm{~d}$ and $250 \mathrm{~d}$ old wildtype $\left(\mathrm{LMP7}^{+/+}\right.$) and APPPS1;LMP7 ${ }^{+/+}$mice (respective littermate control LMP7 ${ }^{-/-}$and APPPS1;LMP7 ${ }^{-1-}$ mice served as a control for antibody specificity) and (b) corresponding densitometric quantification (right panel; $n=3-5$ mice per group, $\left(\mathrm{LMP}^{+/+}\right.$: 49d vs. 250d; $p=0.0253 ; \mathrm{LMP7}^{+/+}$vs. APPPS1;LMP7 $7^{+/+}: 49 \mathrm{~d} \mathrm{~ns} ; 120 \mathrm{~d} p=0.0222 ; 250 \mathrm{~d} p=0.0065$; two-way ANOVA followed by Bonferroni post-tests). c Native PAGE analysis of brain homogenates from $\mathrm{LMP}^{+/+}$and APPPS1;LMP7 ${ }^{+/+}$mice. Proteasome complexes were visualized by western blotting for the iP subunit LMP7. d Total 265 chymotryptic peptide-hydrolyzing activity was analyzed in brain homogenates from $\mathrm{LMP7}^{+/+}, \mathrm{LMP7}^{-/-}, \mathrm{APPPS1}_{\mathrm{LMP7}}{ }^{+/+}$and respective littermate APPPS1;LMP7 ${ }^{-/-}$mice using Suc-LLVY-AMC peptide hydrolysis ( $n=5$ per

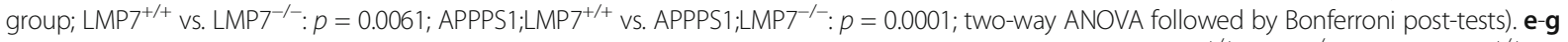
Quantitative PCR analysis of PSMB8, PSMB9, PSMB10, is 15, cxcl10, Ifn- $a$ and Ifn- $\beta$ from whole brain tissue of LMP7 ${ }^{+/+}, \mathrm{LMP7}^{-/-}$, APPPS1;LMP7 $7^{+/+}$and respective littermate APPPS1;LMP7 ${ }^{-/}$mice $\left(n=5\right.$ per group; PSMB8 120d: $\mathrm{LMP7}^{+/+}$vs. APPPS1;LMP7 ${ }^{+/+}: p=0.0020 ; 250 \mathrm{~d}: \mathrm{LMP7}^{+/+} \mathrm{vs}$ APPPS1;LMP7 ${ }^{+/+}: p=0.0162 ;$ PSMB9 120d: $\mathrm{LMP}^{+/+}$vs. APPPS1;LMP7 $7^{+/+}: p=0.0041 ; 250 \mathrm{~d}: \mathrm{LMP}^{+/+}$vs. APPPS1;LMP7 $7^{+/+}: p=0.0014 ;$ isg $15120 \mathrm{~d}:$

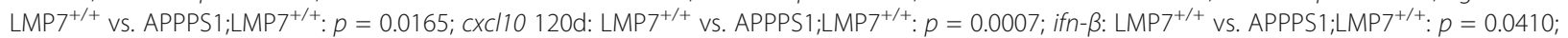
two-way ANOVA followed by Bonferroni post-tests). $\mathbf{h}$ Western blot analysis of poly-ubiquitin conjugates in brain homogenates of 120 days old APPPS1;LMP7 ${ }^{+/+}$and respective littermate APPPS1;LMP7 ${ }^{-/}$mice as well as age-matched wild-type and $\mathrm{LMP7}^{-/-}$mice and (b) corresponding densitometric quantification ( $n=3-5$ mice per group; ${ }^{* * *} p=0.001$, one-way ANOVA followed by Bonferroni post-tests). (j) Western blot analysis of oxidant-damaged proteins in brain homogenates of 120 days old APPPS1;LMP7 ${ }^{+/+}$and respective littermate APPPS1;LMP7 ${ }^{-/-}$mice, as well as agematched wild-type and $\mathrm{LMP7}^{-/-}$mice using carbonyl-detection and (k) corresponding densitometric quantification $\left(n=2-4\right.$ mice per group; LMP7 $7^{+/+}$ vs. $\mathrm{LMPT}^{-1-}: p=0.0096 ; \mathrm{LMP7}^{+/+}$vs. APPPS1;LMP7 ${ }^{+/+}: p=0.0066 ; \mathrm{LMP7}^{+/+}$vs. APPPS1;LMP7 ${ }^{-1-}: p=0.0023 ;{ }^{* *} p<0.01$, one-way ANOVA followed by Bonferroni post-tests). ( $\mathrm{nd}=$ not detected and $\mathrm{na}=$ not analyzed)
\end{abstract}

\section{Microglia activity and pro-inflammatory cytokine levels are reduced by iP deficiency in APPPS1 mice}

Next we analyzed the effect of LMP7 deficiency on inflammation in APPPS1 mice. Since iP activation upon A $\beta$-pathology has been described mainly in glial cells, we analyzed the effect of iP deficiency on microgliosis in APPPS1 mice by stereologically analyzing microglia cells (Fig. 4a and b). Despite there being no difference in $A \beta$ plaque burden, iP deficient APPPS1 mice displayed a significant reduction in the number of and percentage of area covered by Iba-1+ microglia cells compared to APPPS1 mice with functional iPs (Fig. $4 \mathrm{a}$ and b, area covered: APPPS1.LMP7 ${ }^{+/+}$vs. APPPS1;LMP7 ${ }^{-/-}: p=0.0135$; unpaired t-test, two-tailed and number of Iba + microglia cells: APPPS1.LMP7 ${ }^{+/+}$vs. APPPS1;LMP7 ${ }^{-/-}: p=0.0286$; unpaired t-test, two-tailed), indicating that iP deficiency changes the microglial response to $A \beta$-pathology. The slight reduction in the number of microglia in APPPS1 mice lacking LMP7 compared to those harboring LMP7 was accompanied by changes in the concentration of pro-inflammatory secreted cytokines in vivo (Fig. 4c and d), with a significant reduction of TNF $\alpha$ and IL-6 levels (TNFa: APPPS1.LMP7 ${ }^{+/+}$vs. APPPS1;LMP7 ${ }^{-1-}$ : $p=0.0079$ and IL-6: APPPS1.LMP7 ${ }^{+/+}$vs. APPPS1;LMP7 ${ }^{-1-}: p=0.0079$, Mann-Whitney test, two-tailed), while IL$1 \beta$, IL-4 and IL-10 levels remained unchanged at 120 days of age (Fig. 4c). However, this cytokine profile changed upon aging and prolonged A $\beta$ exposure. Aged (250 days old) APPPS1 mice deficient in iPs still displayed a significant reduction of TNF $\alpha$ in soluble brain extracts (TNF $\alpha$ : APPPS1.LMP7 $^{+/+}$vs. APPPS1;LMP7 ${ }^{-/-}: p=0.0260$; MannWhitney test, two-tailed), while IL-6 levels were unchanged. In contrast, the anti-inflammatory cytokines IL-4 and IL-10 levels were significantly increased in soluble brain extracts of aged LMP7-deficient APPPS1 mice
(250 days old; Fig. 4d, (IL-4: APPPS1.LMP7 $7^{+/+}$vs. APPPS1;LMP7 ${ }^{-/-}: p=0.0223$ and IL-10: APPPS1.LMP7 ${ }^{+/+}$ vs. APPPS1;LMP7 ${ }^{-1-}: p=0.0317$; Mann-Whitney test, two-tailed). The observed change in the microglia compartment was accompanied by an increase in astrogliosis in iP deficient APPPS1 mice compared to iP competent APPPS1 mice (Fig. 4e and f, area covered by GFAP+ astrocytes, APPPS1.LMP7 $7^{+/+}$vs. APPPS1;LMP7 ${ }^{-/-}: n=5$ mice per group, ${ }^{* * *} p=0.001$, two-tailed Student's t-test), most likely secondary to the changes in microglia response and cytokine secretion. Taken together, our results indicate a role for iPs in modulating the glial response during the course of A $\beta$-pathology in APPPS1 mice.

\section{Microglia deficient in LMP7 subunits elicit attenuated cytokine responses in vitro}

Since we observed a modulation of microglia activity in APPPS1 mice deficient in LMP7 in vivo, we examined the effect of iP deficiency on microglia cytokine release in vitro by culturing microglia isolated from mouse brain tissues (Fig. 5a). As expected, primary microglia isolated from 120 day old APPPS1 mice exhibited significantly elevated levels of the pro-inflammatory cytokines TNF $\alpha$ and IL- 6 at baseline compared to wildtype littermate control animals (Fig. 5b, TNF $\alpha$ : LMP7 ${ }^{+/+}$vs. APPPS1;LMP7 ${ }^{+/+}: p=0.0275 ; \mathrm{LMP7}^{-/-}$vs. APPPS1;LMP7 ${ }^{+/+}: p=0.0394 ;$ APPPS1;LMP7 ${ }^{-/-}$vs. APPPS1;LMP7 ${ }^{+/+}: p=0.0252 ;$ IL-6: $\mathrm{LMP}^{+/+}$vs. APPPS1;LMP7 ${ }^{+/+}: p=0.0095 ; \mathrm{LMP7}^{-/-}$vs. $\mathrm{APPPS}_{;} ; \mathrm{LMP}^{+/+}: \quad p=0.0307 ; \mathrm{APPPS} 1 ; \mathrm{LMP}^{-/-}$vs. APPPS1;LMP7 ${ }^{+/+}: p=0.0471$; one-way ANOVA followed by Bonferroni post-tests). While iP deficiency tended to increase microglia cytokine release in the nonpathological context, microglia isolated from APPPS1 mice deficient in iPs secreted significantly reduced amounts of pro-inflammatory cytokines TNF $\alpha$ and IL-6 
a APPPS1;LMP7 ${ }^{+/+}$APPPS1;LMP7 $7^{-1}$

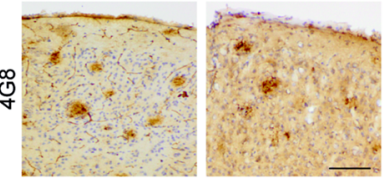
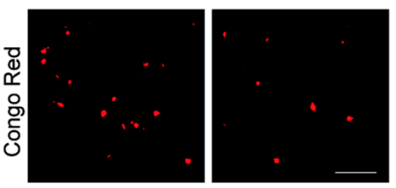

C

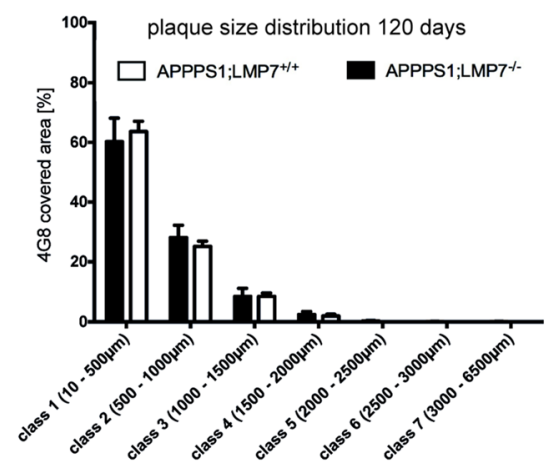

$250 \mathrm{~d}$

APPPS1;LMP7 ${ }^{+/+}$APPPS1;:LMP7-*
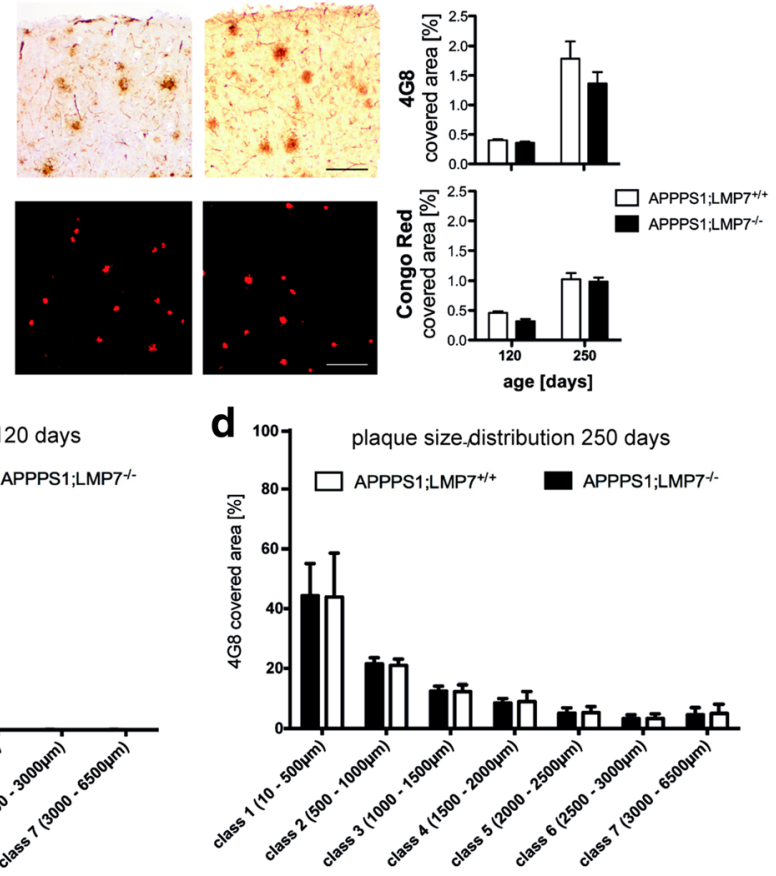

e

total $A \beta$

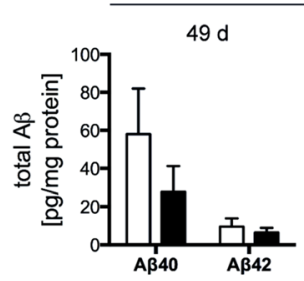

f $120 \mathrm{~d}$
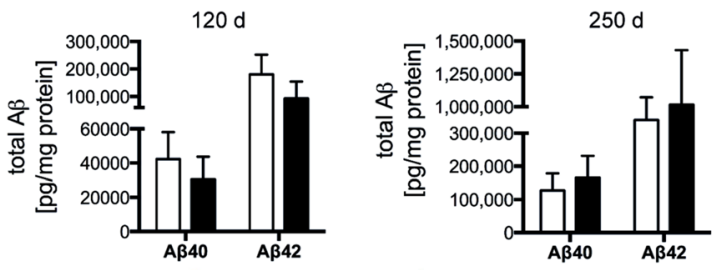

$\square$ APPPS1;LMP7 ${ }^{+/+} \square$ APPPS1;LMP7 $^{-1}$ $A \beta 40$ $A \beta 42$
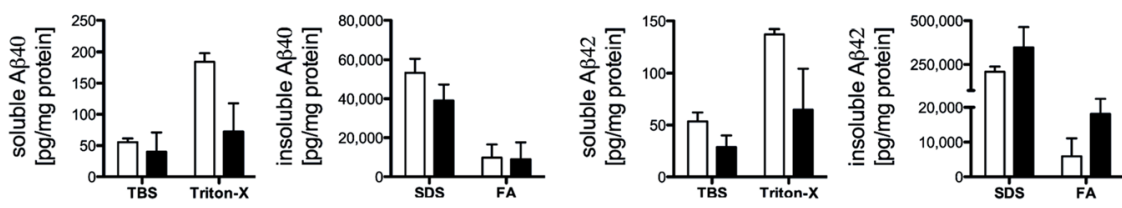

g $250 \mathrm{~d}$ $A \beta 40$

APPPS $1 ; \mathrm{LMP} 7^{-1-}$
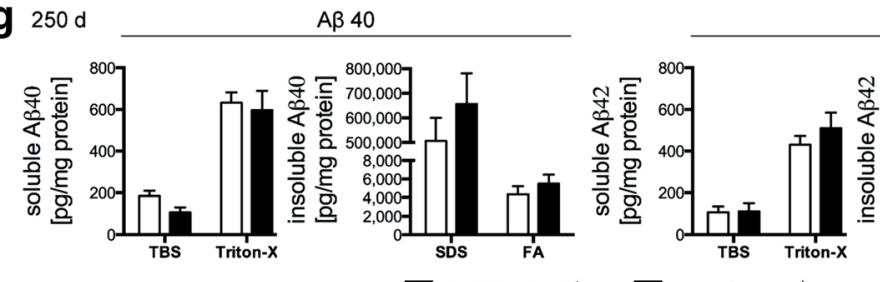

$A \beta 42$

$\square$ APPPS1;:LMP7 ${ }^{+/+}$

APPPS1;LMP7\%

Fig. 2 (See legend on next page.) 
(See figure on previous page.)

Fig. 2 iP subunit deficiency has no impact on cerebral Aß burden in young and aged APPPS1 mice. a Representative images of diffuse plaques (4G8 antibody immunohistochemistry) and congophilic core plaques assessed by Congo Red staining in cortical sections of young and aged $\mathrm{APPPS1}_{\mathrm{LMP7}}{ }^{+/+}$and respective littermate APPPS1;LMP7 ${ }^{-/-}$mice (scale bar $100 \mu \mathrm{m}$ ) and (b) corresponding stereomorphological quantification of $A \beta$ plaque burden ( $n=4-8$ mice per group, $p>0.05$, Mann-Whitney test). $\mathbf{c}$ Plaque size distribution analysis using the CellSense software in the cerebral cortex of 120 days old APPPS1;LMP7 ${ }^{+/+}$and respective littermate APPPS1;LMP7 ${ }^{-/-}$mice and (d) aged 250 days old APPPS1;LMP7 $7^{+/+}$ and respective littermate APPPS1;LMP7 ${ }^{-1-}$ mice ( $n=3-5$ mice per group, $p>0.05$, two-way ANOVA, followed by Bonferroni post-tests). e Total amounts of soluble and insoluble $A \beta_{1-40}$ and $A \beta_{1-42}$ species in brain homogenates of pre-plaque depositing, young 120 days old and aged250 days old APPPS1;LMP7 ${ }^{+/+}$and respective littermate APPPS1;LMP7 ${ }^{-/}$mice assessed by MSD 96-Well MULTI-SPOT ${ }^{\circledast}$ Human (6E10) Abeta Triplex Assay (Meso Scale Discovery) ( $n=4-8$ mice per group, $p>0.05$, one-way ANOVA followed by Bonferroni post-tests). $\mathbf{f}$ and (g) Amount of soluble and insoluble $A \beta_{1-40}$ and $A \beta_{1-42}$ species calculated from individual protein fractions assessed by MSD 96-Well MULTI-SPOT ${ }^{\circledR}$ Human (6E10) Abeta Triplex Assay (Meso Scale Discovery) in brain homogenates of (f) young 120 days old APPPS1;LMP7 ${ }^{+/+}$and respective littermate APPPS1;LMP7 ${ }^{-/-}$ mice ( $n=4-6$ mice per group, $p>0.05$, Mann-Whitney test) and (g) aged 250 days old APPPS1;LMP7 ${ }^{+/+}$and respective littermate APPPS1;LMP7 ${ }^{-/-}$ mice $(n=5$ mice per group, $p>0.05$, Mann-Whitney test)

(TNFa: $\quad$ APPPS1;LMP7 ${ }^{-/-} \quad$ vs. APPPS1;LMP7 ${ }^{+/+}$: $p=0.0252$ and IL-6: APPPS1;LMP7 ${ }^{-/-}$vs. APPPS1; $\mathrm{LMP}^{+/+}: p=0.0471$; one-way ANOVA followed by Bonferroni post-tests), whereas levels of IL-1 $\beta$ and IL-10 were only slightly affected (Fig. 5b). The cytokine profiles observed in isolated microglia in vitro corresponded to the cytokine levels detected in whole brain homogenates in vivo (Fig. 4c and d). After additional stimulation with LPS to fully induce iP expression, secretion of all measured cytokines was significantly attenuated in APPPS1 mice lacking LMP7 compared to microglia isolated from iP competent APPPS1 mice (Fig. 5c, TNF $\alpha$ : $\mathrm{LMP7}^{+/+}$vs.

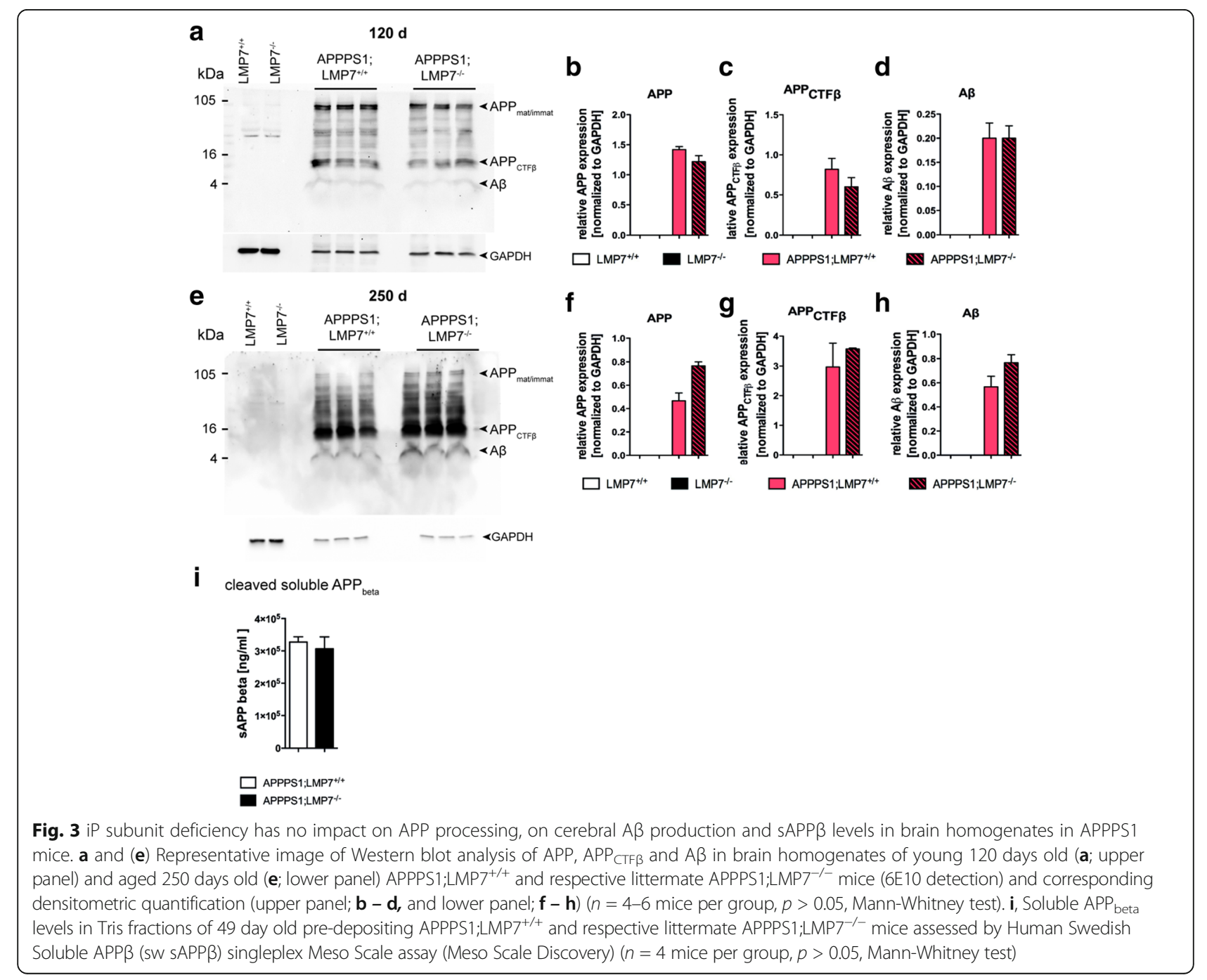


a

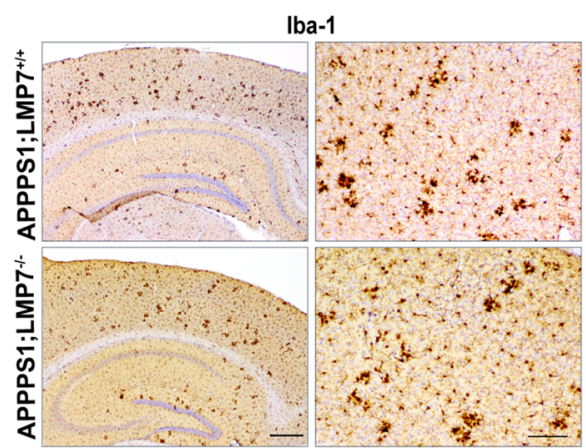

C

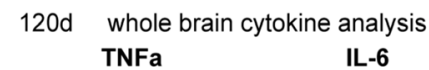

b Iba-1 area covered number of Iba- $1+$ cells

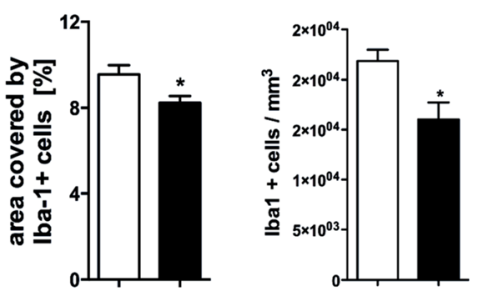

APPPS1;LMP7 $7^{+1+}$

APPPS1;LMP7 +-

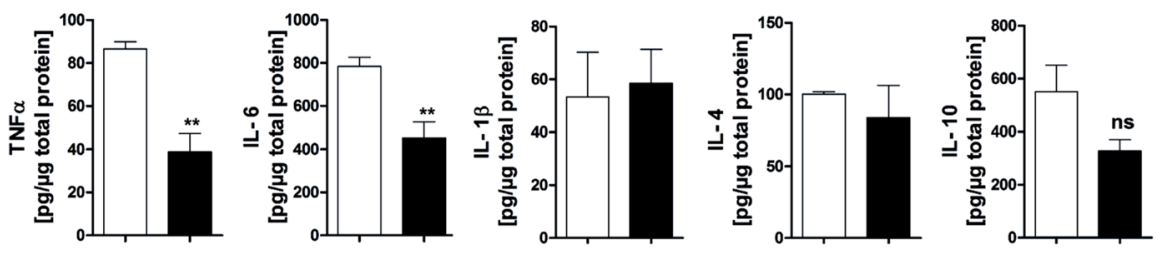

$\square$ APPPS1;:LMP7 ${ }^{+/+}$APPPS1;:LMP7

d 250d whole brain cytokine analysis TNFa

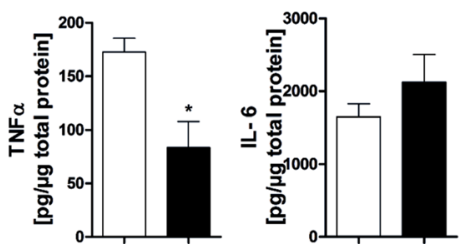

IL-6

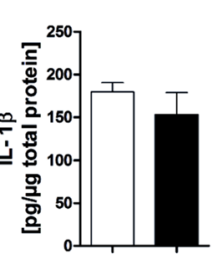

IL-4

IL-10

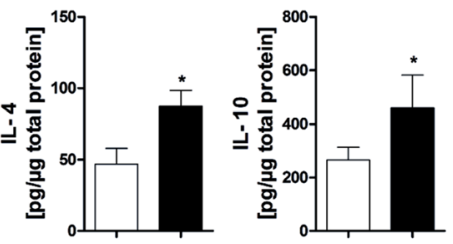

$\square$ APPPS1;LMP7 $7^{+/+}$

APPPS1;LMP7 ${ }^{-1}$

e

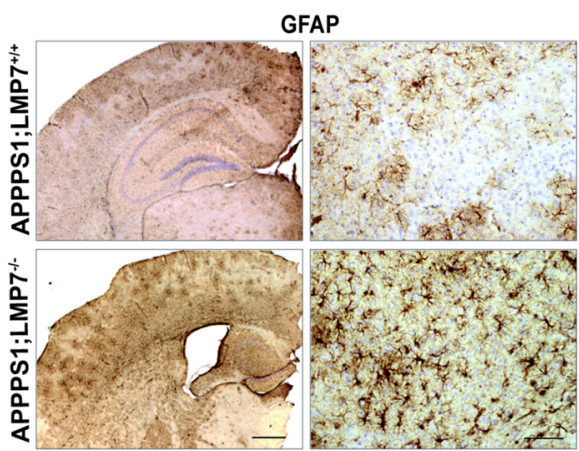

f GFAP area covered

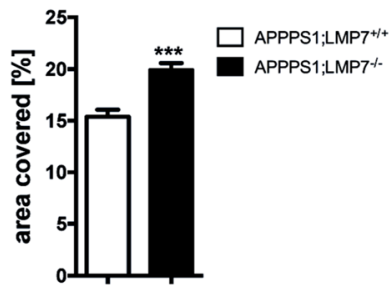


(See figure on previous page.)

Fig. 4 iP subunit deficiency changes microgliosis and the inflammatory milieu in APPPS1 mice. a Representative images of Iba- 1 immunohistochemistry in cortical sections of 120 days old APPPS1;LMP7 ${ }^{+/+}$and respective littermate APPPS1;LMP7 ${ }^{-/}$mice (left panels: scale bar $500 \mu \mathrm{m}$; right panels: scale bar $100 \mu \mathrm{m})$. b Corresponding stereomorphological quantification of the Iba-1 area covered and numbers of Iba-1+ cells at 120 days of age ( $n=4-5$ mice per group, area covered: APPPS1.LMP7 ${ }^{+/+}$vs. APPPS1;LMP7 ${ }^{-/-}: p=0.0135$; number of Iba + microglia cells: APPPS1.LMP7 ${ }^{+/+}$ vs. APPPS1;LMP7 ${ }^{-1-}: p=0.0286$; unpaired t-test, two-tailed). c Analysis of whole brain cytokine levels assessed by Meso Scale V-PLEX Plus Proinflammatory Panel 1 (mouse) kit in brain homogenates of 120 days of age APPPS1;LMP7 $7^{+/+}$and respective littermate APPPS1;LMP7 ${ }^{-/-}$mice ( $n=4-5$ mice per group, TNFa: APPPS1.LMP7 ${ }^{+/+}$vs. APPPS1;LMP7 ${ }^{-/-}: p=0.0079 ;$ IL-6: APPPS1.LMP7 ${ }^{+/+}$vs. APPPS1;LMP7 ${ }^{-1-}: p=0.0079$, Mann- $^{-}$ Whitney test). $\mathbf{d}$ Analysis of whole brain cytokine levels assessed by Meso Scale V-PLEX Plus Pro-inflammatory Panel 1 (mouse) kit in soluble brain homogenates of 250 days of age APPPS1;LMP7 ${ }^{+/+}$and respective littermate APPPS1;LMP7 ${ }^{-/-}$mice $(n=4-5$ mice per group, TNFa: APPPS1.LMP7

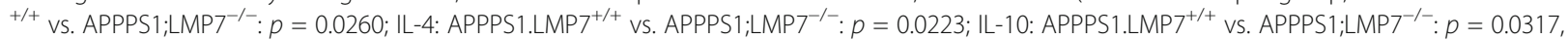
Mann-Whitney test). e Representative images of GFAP-positive astrocytes detected by immunohistochemistry in cerebal cortical sections. f Stereomorphological quantification of the GFAP area covered in APPPS1.LMP7 $7^{+/+}$and respective littermate APPPS1;LMP7 $7^{-1-}$ mice $(n=5$ mice per group, ${ }^{* * *} p=0.001$, two-tailed Student's t-test)

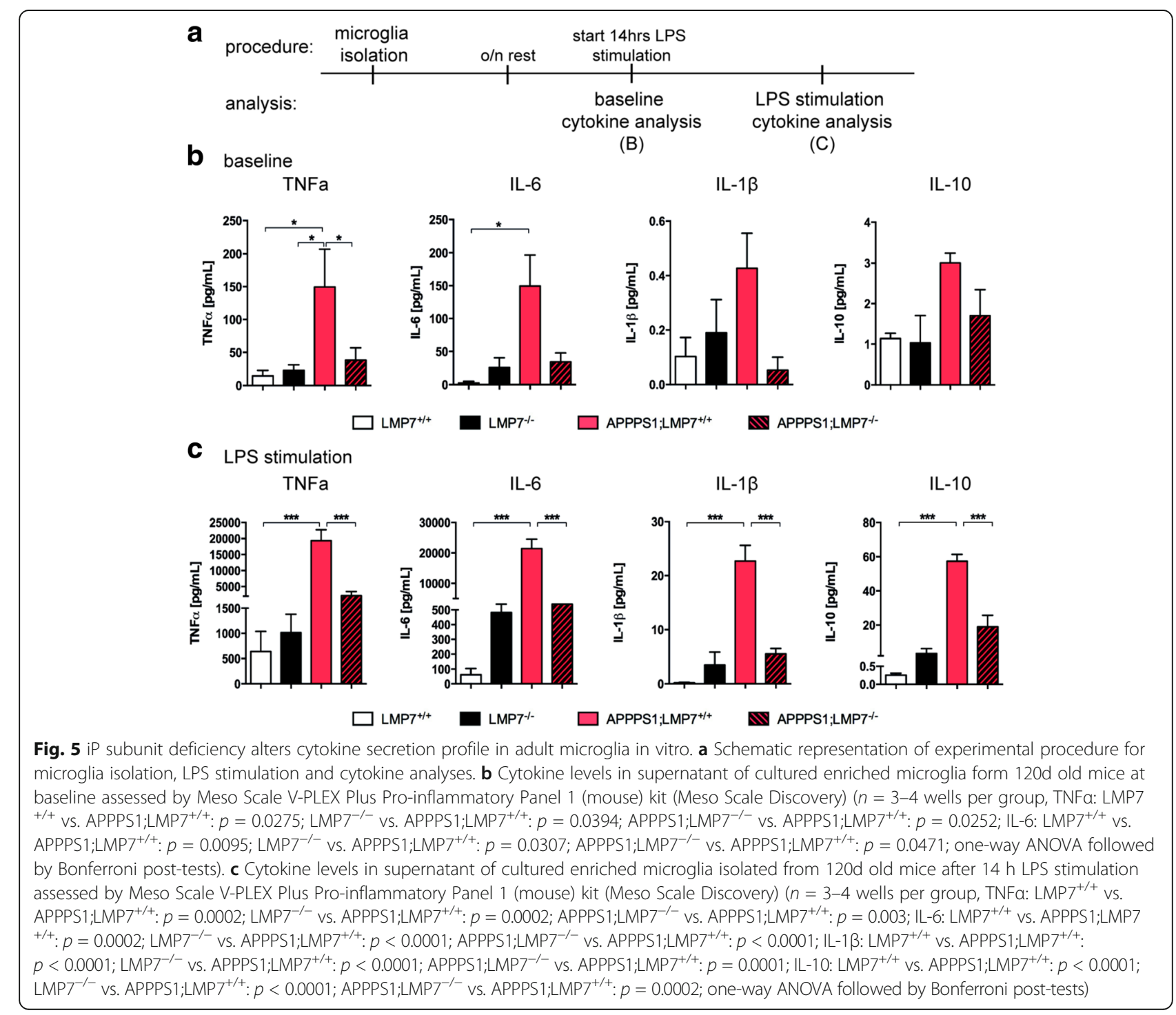


$\mathrm{APPPS} 1 ; \mathrm{LMP}^{+/+}: p=0.0002 ; \mathrm{LMP}^{-/-}$vs. APPPS1;LMP7 ${ }^{+/+}: p=0.0002 ; \mathrm{APPPS} 1 ; \mathrm{LMP}^{-/-}$vs. APPPS1;LMP7 ${ }^{+/+}:$ $p=0.003 ; \quad$ IL-6: $\mathrm{LMP}^{+/+}$vs. APPPS1;LMP7 ${ }^{+/+}$: $p=0.0002 ; \mathrm{LMP}^{-/-}$vs. APPPS1;LMP7 ${ }^{+/+}: p<0.0001$; APPPS1;LMP7 ${ }^{-/-}$vs. APPPS1;LMP7 $7^{+/+}: p<0.0001 ; \mathrm{IL}-1 \beta$ : $\mathrm{LMP}^{+/+}$vs. APPPS1;LMP7 ${ }^{+/+}: p<0.0001 ; \mathrm{LMP}^{-/-}$vs. $\mathrm{APPPS}_{;} \mathrm{LMP}^{+/+}: \quad p<0.0001 ; \mathrm{APPPS} 1 ; \mathrm{LMP}^{-/-}$vs. APPPS1;LMP7 ${ }^{+/+}: \quad p=0.0001 ; \quad$ IL-10: $\mathrm{LMP}^{+/+}$vs. APPPS1;LMP7 ${ }^{+/+}: p<0.0001 ; \mathrm{LMP}^{-/-}$vs. APPPS1;LMP7 ${ }^{+/+}: p<0.0001$; APPPS1;LMP7 ${ }^{-/-}$vs. APPPS1;LMP7 ${ }^{+/+}:$ $p=0.0002$; one-way ANOVA followed by Bonferroni post-tests). These data demonstrate that the iP is involved in modulating microglia cytokine secretion in the context of $A \beta$-pathology and upon exogenous stimulation.

\section{Cognitive deficts are attenuated by iP deficiency in APPPS1 mice}

To determine whether iP deficiency and its subsequent reduction in pro-inflammatory cytokines alters cognitive function in AD model mice, we performed a variety of behavioral tests with APPPS1 mice lacking or harboring LMP7.

When examining performance in the novel object test, a measure for cortical dependent memory function, APPPS1 mice deficient in iP activity showed increased exploration of and visits to the novel objects (Fig. 6a) compared to APPPS1 mice with functional iP activity (duration: $\mathrm{LMP}^{+/+}$vs. APPPS1;LMP7 ${ }^{+/+}: p=0.0475$; visits: $\mathrm{LMP}^{+/+}$vs. APPPS1;LMP7 ${ }^{+/+}: p=0.0209$; oneway ANOVA followed by Bonferroni post-tests), indicating improvement of cortical memory in iP deficient APPPS1 mice. Analysis of spatial memory performance in the Barnes maze test revealed normal learning and memory abilities of wildtype and iP deficient mice. APPPS1 mice with normal iP activity showed significant impairment in learning the task (Fig. 6c, day 4: $\mathrm{LMP7}^{+/+}$ vs. APPPS1;LMP7 ${ }^{+/+}: p=0.0033 ; \mathrm{LMP}^{+/+}$vs. APPPS1; $\mathrm{LMP7}^{-/-}: p=0.2096$; two-way ANOVA followed by Bonferroni post-tests), while APPPS1 mice deficient in iPs showed a slight amelioration of these learning deficits. This was demonstrated by a reduced latency to locate the escape chamber during the short-term memory retention trial compared to cognitively-impaired APPPS1 mice with functional iP activity (Fig. 6d, short-term retention: $\mathrm{LMP}^{+/+}$vs. APPPS1;LMP7 $7^{+/+}: p=0.0067$ and $\mathrm{LMP}^{+/+}$vs. APPPS1;LMP7 ${ }^{-/-}: p=0.0322$; long-term retention: $\mathrm{LMP7}^{+/+}$vs. APPPS1;LMP7 $7^{+/+}: p=0.0022$; $\mathrm{APPPS} 1 ; \mathrm{LMP}^{-/-}$vs. APPPS1;LMP7 ${ }^{+/+}: p=0.0548$; $\mathrm{LMP}^{+/+}$vs. APPPS1;LMP7 ${ }^{+/+}: p=0.0322 ; \mathrm{LMP}^{+/+}$vs. APPPS1;LMP7 ${ }^{-l-}: \quad p=0.0178 ;$ one-way ANOVA followed by Bonferroni post-tests), indicating an mild improvement of hippocampus-dependent memory impairment by iP deficiency in APPPS1 mice.
Taken together, these data indicate a beneficial effect of iP deficiency on cognitive performance in mice developing AD-like A $\beta$-pathology, which coincides with reduced secretion of pro-inflammatory cytokines upon modulation of iP function (Fig. 4a-e).

\section{Discussion}

We herein demonstrate that elements of the proteasome system, namely iP subunits such as LMP7, are increased in the CNS upon aging and that this phenomenon is further accelerated by concomitant development of $\mathrm{AD}$ associated A $\beta$-pathology in APPPS1 mice, most likely mediated through type I interferon induction. Deletion of functional iPs in APPPS1 mice modulates the A $\beta$ associated inflammatory signature resulting in a mild ameloriation of the pathology-associated behavioral phenotype, which is in line with the data of the Green lab [13, 51].

The proteasome system consisting of various isoforms is a major defense mechanism against pathologic changes in proteostasis and essential for cellular integrity. Thus, it is expressed in all cells, including neurons, microglia and astrocytes in the brain [31]. However, the expression and activity of the various proteasome isoforms varies between cell types. Induction of iP expression was detected in cultured and IFNY treated microglia in vitro [52] as well as in plaque associated microglia and astrocytes in vivo [41]. Whereas standard proteasome (sP) activity is reduced in aging [26] and in neurodegenerative disorders $[27,48]$ possibly leading to protein aggregation, oxidation and neuronal degeneration, the iP has been observed to be upregulated in human brains in the context of ageing, AD and Huntington's disease $[16,37]$. However, the impact of in vivo iP inhibition or deficiency on the development and progression of neurodegenerative diseases such as AD has not been studied to date.

Rodent studies have generated inconsistent data showing decreased, unaltered and increased proteasomal capacity during the course of aging $[20,57]$. In the context of $\mathrm{AD}$, iP activity was shown to be impaired in a mouse model exhibiting A $\beta$-pathology [2], despite increased expression of iP subunits. In line with the latter finding, we also demonstrate herein that expression levels of $\beta 5 \mathrm{i} / \mathrm{LMP} 7 / \mathrm{PSMB} 8$ iP subunits are increased upon aging, which are further enhanced by concomitant deposition of $A \beta$ in mice exhibiting AD-like pathology. This is also true for the expression of the $\beta 1 \mathrm{i} / \mathrm{LMP} 2 / P S M B 9$ gene encoding another IP subunit. Besides the changes in gene expression, we can also show that the chymotryptic-like activity is increased due to increased $A \beta$-pathology, which is in accordance with a study by Orre and colleagues demonstrating that proteasomal activity is upregulated in APP/PS1 mice [41]. It is very likely that the choice of animal models, of assays used to measure iP activity, and the choice of time point 


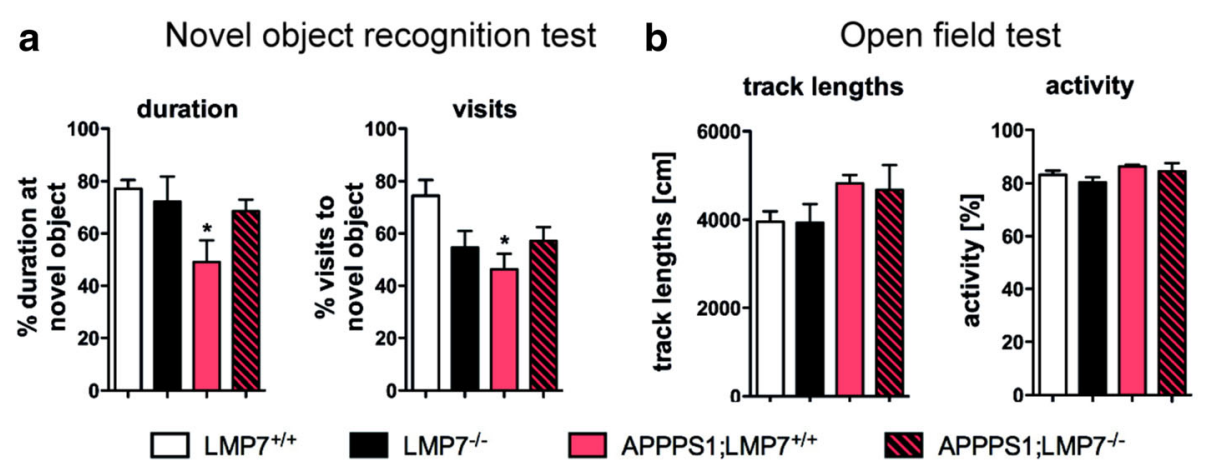

C

Barnes maze training trials latency to target during training trials
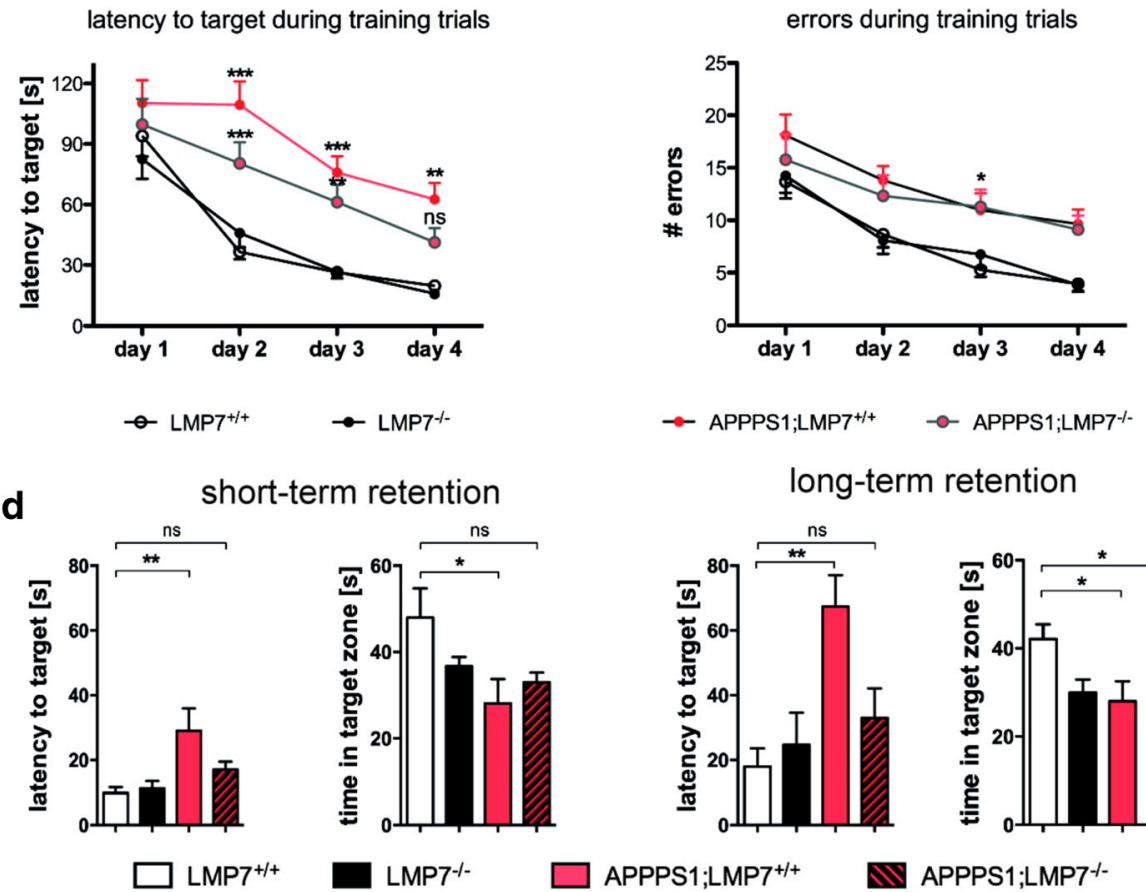

long-term retention
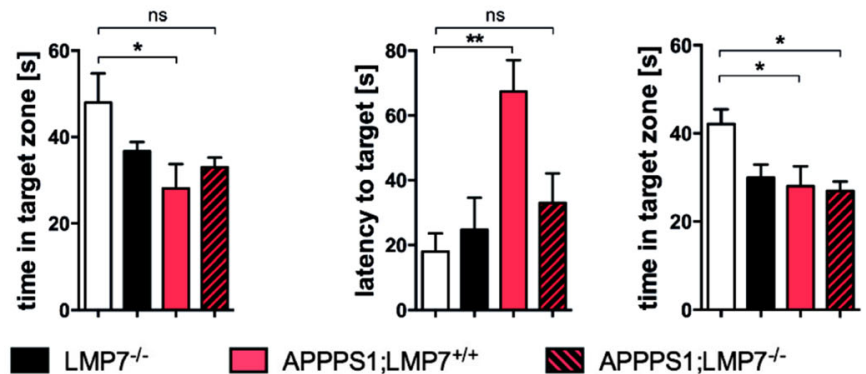

Fig. 6 Improved cognitive function of APPPS1 mice upon iP deficiency. a Aged APPPS1;LMP7 ${ }^{+/+}$and respective littermate APPPS1;LMP7 ${ }^{-/-}$mice $^{-}$ underwent behavioral tests for cognition, $\mathrm{LMP}^{+/+}$and $\mathrm{LMP7}^{-/-}$mice served as controls. Percentage of time spent exploring the novel object and percentage of visits to the new object in the Novel object recognition test $\left(n=8-10\right.$ mice per group; duration: LMP7 $7^{+/+} \mathrm{VS}_{\text {. APPPS1; LMP7 }}^{+/+}$: $p=0.0475$; visits: LMP7 ${ }^{+/+}$vs. APPPS1;LMP7 ${ }^{+/+}: p=0.0209$; one-way ANOVA followed by Bonferroni post-tests). $\mathbf{b}$ Quantification of recorded track lengths and respective mouse activity of APPPS1;LMP7 ${ }^{+/+}$and respective littermate APPPS1;LMP7 ${ }^{-/}$mice analyzed in the Open field arena ( $n=8-10$ mice per group; $\mathrm{p}>\mathrm{p}$ 0.05; one-way ANOVA followed by Bonferroni post-tests). $\mathbf{c}$ Latency to target and number of errors during training trials during the Barnes maze paradigm ( $n=8-10$ mice per group; day 4: $\mathrm{LMP7}^{+/+} \mathrm{vs}$. APPPS1;LMP7 ${ }^{+/+}: p=0.0033 ; \mathrm{LMP7}^{+/+} \mathrm{Vs}^{\text {. APPPS1; LMP7 }}{ }^{-/-}$: $p=0.2096$; two-way ANOVA followed by Bonferroni post-tests). $\mathbf{d}$ Short-term and long-term memory retention trail: Quantification of latency to reach the target and total time spent in the target zone during the Barnes maze paradigm $\left(n=8-10\right.$ mice per group; short-term retention: LMP7 $7^{+/+}$vs. APPPS1;LMP7 $7^{+/+}: p=0.0067 ; \mathrm{LMP7}^{+/+}$vs. APPPS1;LMP7 ${ }^{+/+}: p=0.0322 ;$ long-term retention: $\mathrm{LMP}^{+/+}$vs. APPPS1;LMP7 $7^{+/+}: p=0.0022 ;$

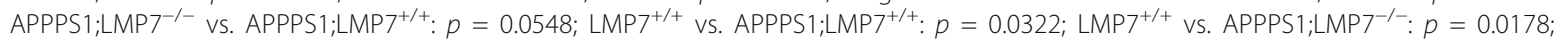
one-way ANOVA followed by Bonferroni post-tests)

of analysis account for some of the discrepancies regarding changes in proteasome activity in previously published studies. In our present study the induction of iP subunits coincided with the transient upregulation of type I IFN and other IFN-stimulated genes, which represents a likely signaling pathway for the induction of iP subunit expression. The induction of type I IFN-production and the chemokine CXCL-10 was previously reported in cells treated with proteasome inhibitors or in PRAAS patient's cells indicating that $A \beta$ deposition impairs proteasome function [8]. Furthermore, the axis of CXCL-10 and its receptor CXCR3 expressed on microglia have been 
implicated in promoting plaque formation and behavioral deficits in APPPS1 mice [30]. In addition, ablation of type I IFN signaling has been shown to preserve cognitive function and cytokine pattern in a mouse model of AD [36].

The LMP7 deficient mouse model was initially used to study the impact of iPs in antigen presention via MHC I molecules. In addition, more recent studies demonstrating a pathogenetically relevant contribution of iPs in inflammation-driven diseases [7, 17, 40,49] not only extended our knowledge on the role of iP, but provided yet another rational to investigate their role in the pathogenesis of $\mathrm{AD}$, since inflammation-mediated processes in $\mathrm{AD}$ are known to partake in disease progression. Deficiency of iP function did not substantially impact $A \beta$ plaque burden and soluble $A \beta$ levels in APPPS1 mice, although there was a trend to reduced soluble $A \beta$ levels at an early disease stage (120d). One possible explanation is that iP-deficient mice may adapt to their loss of iP activity by upregulation of sP activity. Moreover, APPPS1 mice are known to overexpress toxic $A \beta$ species rapidly and at very high levels, thus eventually overriding rather small effects of iP deficiency on $A \beta$ plaque pathology.

Microglia are known to be key in promoting the pathogenetically relevant contribution of the immune system in AD by a vast release of inflammatory molecules. Secretion of pro-inflammatory cytokines by microglia and associated changes in phagocytic and neuroprotective properties are a major contributing factor to the recently recognized "cellular" phase of Alzheimer's disease [14]. Upon deleting iPs in APPPS1 mice we observed changes in cytokine secretion of microglia which are likely due to an altered control of regulatory factors of the nuclear factor- $\mathrm{k} B$ $(\mathrm{NF} \kappa \mathrm{B})$ family that are important for cytokine release $[4,6,9,39,53]$. In line with our observation in the CNS, selective inhibition of $\beta 5 \mathrm{i} / \mathrm{LMP7}$ in activated peripheral blood mononuclear cells (PBMCs) led to a downregulation of cytokine production via the $\mathrm{NF \kappa B}$ pathway [39]. LPS-induced signaling pathways were also significantly reduced in peritoneal macrophages lacking immunoproteasome subunits [46] indicating an important role for the iP in modulating the $\mathrm{NF \kappa B}$ signaling pathway and therefore cytokine release. Specifically, increased activity of iPs results in enhanced degradation of NFkB inhibitor $\alpha(\mathrm{IkB} \alpha)$, which in turn is more stable in the context of iP-deficiency [40, 49].

The observed changes in microglial activation and cytokine secretion upon $\beta 5 \mathrm{i} / \mathrm{LMP7/PSMB8}$ deficiency were accompanied by an increase in activated astrocytes. Since microglial cytokines are known to modulate the activation state of astrocytes $[32,50]$, these changes are most likely secondary to the altered microglial cytokine secretion profile, although we cannot exclude a direct effect of $\beta 5 \mathrm{i} / \mathrm{LMP} 7 /$ PSMB8 deficiency on astrocytes.
While CNS-derived soluble immune factors including pro-inflammatory cytokines like IL-1 $\beta$, TNF $\alpha$ and IL-6 have been studied intensely [10, 11, 21, 23, 29, 52, 55], their role in $\mathrm{AD}$ is still a matter of debate, also due to the fact that the respective results - at least for some of the analyzed cytokines - is not always consistent [43]. Several studies altered cytokine levels through genetic manipulation of pro- and anti-inflammatory molecules with the aim of modulating chronic inflammation and altering $\mathrm{A} \beta$ plaque burden in transgenic $\mathrm{AD}$-like mice $[10,11,21,23,29,55]$. The diverse role of cytokines in the progression of $\mathrm{AD}$-like pathology is underscored by recent observations showing that overexpression of the anti-inflammatory cytokine IL-10 negatively affected cognitive function [11], whereas IL-10 deficiency significantly restored cognitive impairment of APPPS1 mice [23]. In line with these later studies, we observed that reduced pro-inflammatory cytokine levels upon iP deficiency in APPPS1 mice were associated with improved cognitive performance, although this recovery in cognition was not accompanied by detectable changes in $A \beta$ plaque pathology. Similarly, pharmacological elimination of microglia resulting in amelioration of cognitive deficits and reducing pro-inflammatory cytokines in AD-like mice did not translate into changes in plaque burden $[13,51]$. Since the amount of amyloid plaque burden in $\mathrm{AD}$ subjects does not necessarily correlate with the level of functional deficits, this further supports the notion that cognitive performance and the amount of amyloid burden do not need to correlate inevitably [5, 47]. On the other hand, studies in AD patients suggest that elevated levels of pro-inflammatory cytokines are associated with impaired cognitive function [10, 11, 21, 35, 55] and highlight the potential of manipulation of this proinflammatory response for improving cognitive function without necessarily targeting $\mathrm{A} \beta$ deposition.

\section{Conclusion}

In conclusion, our data demonstrate that iP deficiency is associated with reduced pro-inflammatory cytokine secretion in vitro and in vivo independent of a major impact on $A \beta$-pathology in a mouse model of AD. The reduction of pro-inflammatory cytokine secretion was accompanied by improvement of $A \beta$-pathology associated cognitive deficits, indicating that manipulation of iP activity may be a novel strategy to manipulate cytokine signaling and improve cognitive function in $\mathrm{AD}$ independent of targeting $\mathrm{A} \beta$ deposition. Furthermore, the development of selective iP inhibitors [39] may allow fine-tuned manipulation of cytokine signaling pathways to make this a viable option for targeting the innate immune response in $\mathrm{AD}$ and other neurodegenerative diseases. 


\section{Acknowledgements}

This work was supported by grants from the Deutsche

Forschungsgemeinschaft (SFB TRR 43, NeuroCure Exc 257 and HE 3130/6-1) to FLH, Deutsche Forschungsgemeinschaft (SFB TRR 43) to EK and PMK, SFB740 and BIH to EK,the Federal Ministry of Education and Research (DLR/ $\mathrm{BMBF}$; Kompetenznetz Degenerative Demenzen) to FLH and SP, and from the Berlin Institute of Health (BIH; Collaborative Research Grant) to FLH The authors thank Carola Ruester for technical assistance.

\section{Authors' contributions}

SP, PMK, EK and FLH conceived the study, LKW, KEG and ES performed experiments, LKW, KEG and SP analyzed data and LKW, KEG, SP, EK and FLH wrote the manuscript. SP, FLH, PMK and EK directed the study. All authors read and approved the final manuscript.

\section{Competing interests}

The authors declare no competing financial interests.

\section{Ethics approval and consent to participate}

All animal experiments were performed in accordance to the national animal protection guidelines approved by the regional offices for health and social services in Berlin (LaGeSo).

\section{Publisher's Note}

Springer Nature remains neutral with regard to jurisdictional claims in published maps and institutional affiliations.

\begin{abstract}
Author details
'Department of Neuropathology, Charité - Universitätsmedizin Berlin, Charitéplatz 1, 10117 Berlin, Germany. ${ }^{2}$ Present Address: Department of Neurology, Brigham and Women's Hospital, Harvard Medical School, Boston, MA, USA. ${ }^{3}$ Institute of Biochemistry, Charité - Universitätsmedizin Berlin, Charitéplatz 1, 10117 Berlin, Germany. ${ }^{4}$ Cluster of Excellence, NeuroCure, Charitéplatz 1, 10117 Berlin, Germany. ${ }^{5}$ Berlin Institute of Health (BIH), Berlin, Germany. ${ }^{6}$ Present Address: Institute of Medical Biochemistry and Molecular Biology, University Medicine Greifswald, Ferdinand-Sauerbruch-Str./ DZ7, 17475 Greifswald, Germany. ${ }^{7}$ Present Address: Department of Pathology and Laboratory Medicine, Hospital of the University of Pennsylvania, Philadelphia, PA, USA
\end{abstract}

\section{Received: 5 June 2017 Accepted: 6 June 2017}

Published online: 24 June 2017

\section{References}

1. Aki M, Shimbara N, Takashina M, Akiyama K, Kagawa S, Tamura T, Tanahashi N, Yoshimura T, Tanaka K, Ichihara A (1994) Interferon-gamma induces different subunit organizations and functional diversity of proteasomes. J Biochem 115:257-269

2. Aso E, Lomoio S, López-González I, Joda L, Carmona M, Fernández-Yagüe N, Moreno J, Juvés S, Pujol A, Pamplona R et al (2012) Amyloid generation and dysfunctional immunoproteasome activation with disease progression in animal model of familial Alzheimer's disease. Brain Pathol 22:636-653. doi:10.1111/j.1750-3639.2011.00560.x

3. Ayyadevara S, Balasubramaniam M, Gao Y, Yu L-R, Alla R, Shmookler Reis R (2014) Proteins in aggregates functionally impact multiple neurodegenerative disease models by forming proteasome-blocking complexes. Aging Cell. doi: 10.1111/acel.12296

4. Baldwin AS (1996) THE NF-kB AND IKB PROTEINS: new discoveries and insights Annu Rev Immunol 14:649-681. doi:10.1146/annurev.immunol.14.1.649

5. Bennett DA, Schneider JA, Arvanitakis Z, Kelly JF, Aggarwal NT, Shah RC, Wilson RS (2006) Neuropathology of older persons without cognitive impairment from two community-based studies. Neurology 66:1837-1844. doi:10.1212/01.wnl.0000219668.47116.e6

6. Bohuslav J, Kravchenko W, Parry GC, Erlich JH, Gerondakis S, Mackman N, Ulevitch RJ (1998) Regulation of an essential innate immune response by the p50 subunit of NF-kappaB. J Clin Invest 102:1645-1652. doi:10.1172/JCl3877

7. Brehm A, Krüger E (2015) Dysfunction in protein clearance by the proteasome: impact on autoinflammatory diseases. Semin Immunopathol 37:323-333. doi:10.1007/s00281-015-0486-4
8. Brehm A, Liu Y, Sheikh A, Marrero B, Omoyinmi E, Zhou Q, Montealegre G, Biancotto A, Reinhardt A, Almeida de Jesus A et al (2015) Additive loss-of-function proteasome subunit mutations in CANDLE/PRAAS patients promote type I IFN production. J Clin Invest 125:4196-4211. doi:10.1172/JCl81260

9. Caamaño J, Hunter CA (2002) NF-kB family of transcription factors: central regulators of innate and adaptive immune functions. Clin Microbiol Rev 15: 414-429. doi:10.1128/CMR.15.3.414-429.2002

10. Chakrabarty P, Jansen-West K, Beccard A, Ceballos-Diaz C, Levites Y, Verbeeck C, Zubair AC, Dickson D, Golde TE, Das P (2010) Massive gliosis induced by interleukin- 6 suppresses Abeta deposition in vivo: evidence against inflammation as a driving force for amyloid deposition. FASEB J 24:548-559

11. Chakrabarty P, Li A, Ceballos-Diaz C, Eddy JA, Funk CC, Moore B, DiNunno N, Rosario AM, Cruz PE, Verbeeck C, et al. (2015) IL-10 Alters Immunoproteostasis in APP Mice, Increasing Plaque Burden and Worsening Cognitive Behavior. Neuron. doi: 10.1016/j.neuron.2014.11.020

12. Ciechanover A, Brundin P (2003) The Ubiquitin Proteasome system in neurodegenerative diseases. Neuron 40:427-446. doi:10.1016/S08966273(03)00606-8

13. Dagher NN, Najafi AR, Kayala KMN, Elmore MRP, White TE, Medeiros R, West BL, Green KN (2015) Colony-stimulating factor 1 receptor inhibition prevents microglial plaque association and improves cognition in 3xTg-AD mice. J Neuroinflammation 12:139. doi:10.1186/s12974-015-0366-9

14. De Strooper B, Karran E, Allen NJ, Ando K, Brion J-P, Stygelbout V, Suain V, Authelet M, Dedecker R, Chanut A et al (2016) The cellular phase of Alzheimer's disease. Cell 164:603-615. doi:10.1016/j.cell.2015.12.056

15. Dennissen FJA, Kholod N, van Leeuwen FW (2012) The ubiquitin proteasome system in neurodegenerative diseases: culprit, accomplice or victim? Prog Neurobiol 96:190-207. doi:10.1016/j.pneurobio.2012.01.003

16. Diaz-Hernandez M, Hernandez F, Martin-Aparicio E, Gomez-Ramos P, Moran MA, Castano JG, Ferrer I, Avila J, Lucas JJ (2003) Neuronal induction of the Immunoproteasome in Huntington's disease. J Neurosci 23:11653-11661

17. Ebstein F, Kloetzel P-M, Krüger E, Seifert U (2012) Emerging roles of immunoproteasomes beyond MHC class I antigen processing. Cell Mol Life Sci 69:2543-2558. doi:10.1007/s00018-012-0938-0

18. Fehling HJ, Swat W, Laplace C, Kühn R, Rajewsky K, Müller U, H von B (1994) MHC class I expression in mice lacking the Proteasome subunit LMP-7. Sci, New Ser 265:1234-1237

19. Forman MS, Farmer J, Johnson JK, Clark CM, Arnold SE, Coslett HB, Chatterjee A, Hurtig HI, Karlawish JH, Rosen HJ et al (2006) Frontotemporal dementia: clinicopathological correlations. Ann Neurol 59:952-962. doi:10.1002/ana.20873

20. Giannini C, Kloß A, Gohlke S, Mishto M, Nicholson TP, Sheppard PW, Kloetzel P-M, Dahlmann B (2013) Poly-Ub-substrate-degradative activity of $26 \mathrm{~S}$ proteasome is not impaired in the aging rat brain. PLoS One 8:e64042. doi:10.1371/journal.pone.0064042

21. Giuliani F, Vernay A, Leuba G, Schenk F (2009) Decreased behavioral impairments in an Alzheimer mice model by interfering with TNFalpha metabolism. Brain Res Bull 80:302-308. doi:10.1016/j. brainresbull.2009.07.009

22. Goldberg AL (2003) Protein degradation and protection against misfolded or damaged proteins. Nature 426:895-899. doi:10.1038/nature02263

23. Guillot-Sestier M-V, Doty KR, Gate D, Rodriguez J, Leung BP, Rezai-Zadeh K, Town T (2015) Il10 deficiency rebalances innate immunity to mitigate Alzheimer-like pathology. Neuron. doi:10.1016/j.neuron.2014.12.068

24. Kandimalla RJ, Anand R, Veeramanikandan R, Wani WY, Prabhakar S, Grover VK, Bharadwaj N, Jain K, Gill KD (2014) CSF ubiquitin as a specific biomarker in Alzheimer's disease. Curr Alzheimer Res 11:340-348

25. Kawarabayashi T, Younkin LH, Saido TC, Shoji M, Ashe KH, Younkin SG (2001) Age-Dependent Changes in Brain, CSF, and Plasma Amyloid Protein in the Tg2576 Transgenic Mouse Model of Alzheimer's Disease. J Neurosci 21:(1529-2401):372-381.

26. Keller J, Huang F, Markesbery W (2000) Decreased levels of proteasome activity and proteasome expression in aging spinal cord. Neuroscience 98:149-156. doi:10.1016/S0306-4522(00)00067-1

27. Keller JN, Hanni KB, Markesbery WR (2001) Impaired Proteasome function in Alzheimer's disease. J Neurochem 75:436-439. doi:10.1046/j. 1471-4159.2000.0750436.x

28. Kloetzel PM (2001) Antigen processing by the proteasome. Nat Rev Mol Cell Biol 2:179-187. doi:10.1038/35056572 
29. Kotilinek LA, Westerman MA, Wang Q, Panizzon K, Lim GP, Simonyi A, Lesne S, Falinska A, Younkin LH, Younkin SG et al (2008) Cyclooxygenase-2 inhibition improves amyloid-beta-mediated suppression of memory and synaptic plasticity. Brain 131:651-664

30. Krauthausen M, Kummer MP, Zimmermann J, Reyes-Irisarri E, Terwel D, Bulic B, Heneka MT, Müller M (2015) CXCR3 promotes plaque formation and behavioral deficits in an Alzheimer's disease model. J Clin Invest 125:365-378. doi:10.1172/JCl66771

31. Kremer M, Henn A, Kolb C, Basler M, Moebius J, Guillaume B, Leist M, Van den Eynde BJ, Groettrup M (2010) Reduced immunoproteasome formation and accumulation of immunoproteasomal precursors in the brains of lymphocytic choriomeningitis virus-infected mice. J Immunol 185:5549-5560. doi:10.4049/jimmunol.1001517

32. Liddelow SA, Guttenplan KA, Clarke LE, Bennett FC, Bohlen CJ, Schirmer L, Bennett ML, Münch AE, Chung W-S, Peterson TC et al (2017) Neurotoxic reactive astrocytes are induced by activated microglia. Nature 541:481-487. doi:10.1038/nature21029

33. Liu Y, Hettinger CL, Zhang D, Rezvani K, Wang X, Wang H (2014) The proteasome function reporter GFPu accumulates in young brains of the APPswe/PS1dE9 Alzheimer's disease mouse model. Cell Mol Neurobiol 34 315-322. doi:10.1007/s10571-013-0022-9

34. Lowe J, Blanchard A, Morrell K, Lennox G, Reynolds L, Billett M, Landon M, Mayer RJ (1988) Ubiquitin is a common factor in intermediate filament inclusion bodies of diverse type in man, including those of Parkinson's disease, Pick's disease, and Alzheimer's disease, as well as Rosenthal fibres in cerebellar astrocytomas, cytoplasmic bodies in m. J Pathol 155:9-15. doi:10. 1002/path.1711550105

35. Lue LF, Rydel R, Brigham EF, Yang LB, Hampel H, Murphy GM, Brachova L, Yan S Du, Walker DG, Shen Y, et al. (2001) Inflammatory repertoire of Alzheimer's disease and nondemented elderly microglia in vitro. Glia 35:72-79. doi: 10.1002/glia.1072

36. Minter MR, Moore Z, Zhang M, Brody KM, Jones NC, Shultz SR, Taylor JM, Crack PJ (2016) Deletion of the type-1 interferon receptor in APPSWE/ PS1 $\triangle$ E9 mice preserves cognitive function and alters glial phenotype. Acta Neuropathol Commun 4:72. doi:10.1186/s40478-016-0341-4

37. Mishto M, Bellavista E, Santoro A, Stolzing A, Ligorio C, Nacmias B, Spazzafumo L, Chiappelli M, Licastro F, Sorbi S et al (2006) Immunoproteasome and LMP2 polymorphism in aged and Alzheimer's disease brains. Neurobiol Aging 27:54-66. doi:10.1016/j.neurobiolaging.2004.12.004

38. Mori H, Kondo J, Ihara Y (1987) Ubiquitin is a component of paired helical filaments in Alzheimer's disease. Science 235:1641-1644

39. Muchamuel T, Basler M, Aujay M A, Suzuki E, Kalim KW, Lauer C, Sylvain C, Ring ER, Shields J, Jiang J, et al. (2009) A selective inhibitor of the immunoproteasome subunit LMP7 blocks cytokine production and attenuates progression of experimental arthritis. Nat Med 15:781-787. doi: 10.1038/nm.1978

40. Opitz E, Koch A, Klingel K, Schmidt F, Prokop S, Rahnefeld A, Sauter M Heppner FL, Völker U, Kandolf R et al (2011) Impairment of immunoproteasome function by $\beta 5 \mathrm{i} / \mathrm{LMP7}$ subunit deficiency results in severe enterovirus myocarditis. PLoS Pathog 7:e1002233. doi:10.1371/journal. ppat.1002233

41. Orre M, Kamphuis W, Dooves S, Kooijman L, Chan ET, Kirk CJ, Dimayuga Smith V, Koot S, Mamber C, Jansen AH et al (2013) Reactive glia show increased immunoproteasome activity in Alzheimer's disease. Brain. doi:10.1093/brain/awt083

42. Perry G, Friedman R, Shaw G, Chau V (1987) Ubiquitin is detected in neurofibrillary tangles and senile plaque neurites of Alzheimer disease brains. Proc Natl Acad Sci U S A 84:3033-3036

43. Prokop S, Miller KR, Heppner FL (2013) Microglia actions in Alzheimer's disease. Acta Neuropathol. doi:10.1007/s00401-013-1182-x

44. Querfurth HW, LaFerla FM (2010) Alzheimer's disease. N Engl J Med 362: 329-344. doi:10.1056/NEJMra0909142

45. Radde R, Bolmont T, Kaeser SA, Coomaraswamy J, Lindau D, Stoltze L, Calhoun ME, Jaggi F, Wolburg H, Gengler S, et al. (2006) Abeta42-driven cerebral amyloidosis in transgenic mice reveals early and robust pathology. EMBO rep 7:940-946. Doi: 7400784 [pii]10.1038/sj.Embor.7400784

46. Reis J, Hassan F, Guan XQ, Shen J, Monaco JJ, Papasian CJ, Qureshi AA, Way CW, Vogel SN, Morrison DC et al (2011) The Immunoproteasomes regulate LPS-induced TRIF/TRAM signaling pathway in Murine macrophages. Cell Biochem Biophys 60:119-126. doi:10.1007/s12013-011-9183-7
47. Schneider JA, Aggarwal NT, Barnes L, Boyle P, Bennett DA (2009) The neuropathology of older persons with and without dementia from community versus clinic cohorts. J Alzheimers Dis 18:691-701. doi:10.3233/ JAD-2009-1227

48. Schubert D, Soucek T, Blouw B (2009) The induction of HIF-1 reduces astrocyte activation by amyloid beta peptide. Eur J Neurosci 29:1323-1334. doi:10.1111/j.1460-9568.2009.06712.x

49. Seifert U, Bialy LP, Ebstein F, Bech-Otschir D, Voigt A, Schröter F, Prozorovski T, Lange N, Steffen J, Rieger M et al (2010) Immunoproteasomes preserve protein homeostasis upon interferon-induced oxidative stress. Cell 142:613-624. doi:10.1016/j.cell.2010.07.036

50. Sofroniew MV, Vinters HV (2010) Astrocytes: biology and pathology. Acta Neuropathol 119:7-35. doi:10.1007/s00401-009-0619-8

51. Spangenberg EE, Lee RJ, Najafi AR, Rice RA, Elmore MRP, Blurton-jones M, West BL, Green KN (2016) Eliminating microglia in Alzheimer 's mice prevents neuronal loss without modulating amyloid- b pathology. 1-17. doi: 10.1093/brain/aww016

52. Stohwasser R, Giesebrecht J, Kraft R, Müller EC, Häusler KG, Kettenmann H, Hanisch UK, Kloetzel PM (2000) Biochemical analysis of proteasomes from mouse microglia: induction of immunoproteasomes by interferon-gamma and lipopolysaccharide. Glia 29:355-365

53. Tak PP, Firestein GS (2001) NF-kB: a key role in inflammatory diseases. J Clin Invest 107:7. doi:10.1172/jci11830

54. Vigneron N, Van den Eynde BJ (2012) Proteasome subtypes and the processing of tumor antigens: increasing antigenic diversity. Curr Opin Immunol 24:84-91. doi:10.1016/j.coi.2011.12.002

55. vom Berg J, Prokop S, Miller KR, Obst J, Kälin RE, Lopategui-Cabezas I, Wegner A, Mair F, Schipke CG, Peters O, et al. (2012) Inhibition of IL-12/IL-23 signaling reduces Alzheimer's disease-like pathology and cognitive decline. Nat Med. doi: 10.1038/nm.2965

56. Welchman RL, Gordon C, Mayer RJ (2005) Ubiquitin and ubiquitin-like proteins as multifunctional signals. Nat Rev Mol Cell Biol 6:599-609. doi:10.1038/nrm1700

57. Zeng B-Y, Medhurst AD, Jackson M, Rose S, Jenner P (2005) Proteasomal activity in brain differs between species and brain regions and changes with age. Mech Ageing Dev 126:760-766. doi:10.1016/j.mad.2005.01.008

58. Zouambia M, Fischer DF, Hobo B, De Vos RAl, Hol EM, Varndell IM, Sheppard PW, Van Leeuwen FW (2008) Proteasome subunit proteins and neuropathology in tauopathies and synucleinopathies: consequences for proteomic analyses. Proteomics 8:1221-1236. doi:10.1002/pmic.200700679

\section{Submit your next manuscript to BioMed Central and we will help you at every step:}

- We accept pre-submission inquiries

- Our selector tool helps you to find the most relevant journal

- We provide round the clock customer support

- Convenient online submission

- Thorough peer review

- Inclusion in PubMed and all major indexing services

- Maximum visibility for your research

Submit your manuscript at www.biomedcentral.com/submit 